\title{
THE RELATIONSHIP BETWEEN DTCA, DRUG REQUESTS AND PRESCRIPTIONS: UNCOVERING VARIATION IN SPECIALTY AND SPACE
}

\author{
by \\ S. Stremersch* \\ V. Landsman** \\ S. Venkataraman*** \\ Working Paper No 16/2012 \\ December 2012
}

\section{Research No. 03910100}

* Erasmus School of Economics, Erasmus University Rotterdam, The Netherlands, and Professor of Marketing, IESE Business School, Universidad de Navarra, Spain

** Faculty of Management, The Leon Recanati Graduate School of Business Administration, Tel Aviv University, Tel Aviv, Israel and at Erasmus School of Economics, Erasmus University Rotterdam, the Netherlands..

*** UNC Kenan-Flagler Business School, University of North Carolina, Chapel Hill.

This paper was partially financed by the Henry Crown Institute of Business Research in Israel.

The Institute's working papers are intended for preliminary circulation of tentative research results. Comments are welcome and should be addressed directly to the authors.

The opinions and conclusions of the authors of this study do not necessarily state or reflect those of The Faculty of Management, Tel Aviv University, or the Henry Crown Institute of Business Research in Israel. 


\title{
The Relationship between DTCA, Drug Requests and Prescriptions: Uncovering Variation in Specialty and Space
}

\author{
Stefan Stremersch, Vardit Landsman, Sriram Venkataraman ${ }^{1}$
}

\footnotetext{
${ }^{1}$ Stefan Stremersch is Chaired Professor of Marketing and Desiderius Erasmus Distinguished Chair of Economics, Erasmus School of Economics, Erasmus University Rotterdam, The Netherlands, and Professor of Marketing, IESE Business School, Universidad de Navarra, Spain. Vardit Landsman is an Assistant Professor of Marketing at the Leon Recanati Graduate School of Business, Tel-Aviv University, Israel, and at Erasmus School of Economics, Erasmus University Rotterdam, the Netherlands. Sriram Venkataraman is Assistant Professor of Marketing at UNC. The authors appreciate the comments of audiences at Tilburg University's 2008 Lustrum Conference, the 2009 European Marketing Academy Conference and the 2009 Informs Marketing Science Conference. They also thank Nuno Camacho, Eelco Kappe, Bas Donkers, Puneet Manchanda, Jan-Benedict Steenkamp and Don Lehmann for comments on earlier versions of this manuscript. This study was funded by the Erasmus Center for Healthcare Business at Erasmus University Rotterdam and the Henry Crown Institute of Business Research in Israel.
} 


\begin{abstract}
Patients increasingly request their physicians to prescribe specific brands of pharmaceutical drugs. Popular belief is that requests are triggered by direct-to-consumer advertising (DTCA). We examine the relationship between DTCA, patient requests and prescriptions for statins. We find that while the effect of requests on prescriptions is significantly positive, the mean effect of DTCA on patient requests is negative, yet very small. More interestingly, both effects show substantial heterogeneity across physicians, which we uncover, using a hierarchical Bayes estimation procedure. We find that specialists receive more requests than primary care physicians but translate them less into prescriptions. In addition, we find that the socio-demographic profile of the area a physician practices in moderates the effects of DTCA on requests and of requests on prescriptions. For instance, physicians from areas with a higher proportion of minorities (i.e., Blacks and Hispanics) receive more requests, which are less triggered by DTCA, and are transferred into fewer prescriptions, than physicians from areas with a lower proportion of minorities. Our results challenge managers to revisit the role of DTCA in stimulating patient requests. At the same time, they may trigger public policy concerns regarding physicians' accommodation of patient requests and the inequalities they may induce.
\end{abstract}

Keywords: pharmaceuticals, advertising, requests, prescriptions, socio-demographics, minorities, race. 


\section{Introduction}

The number of patients who have requested their physicians to prescribe a pharmaceutical drug by brand name has steadily increased, both in the United States (Calabro 2003, Henderson 2002, Medical Marketing and Media 2002) and abroad (Weiss et al. 1996). This increase fits the societal trend of increasing patient involvement and empowerment in medical decision-making (Camacho, Landsman and Stremersch 2010, Hollon 1999, Kravitz et al. 2003, Lupton 1997). Drug requests by brand name are commonly believed to have a positive effect on the number of prescriptions for the requested brand. Previous research has demonstrated such positive effects of drug requests mostly using surveys among physicians, physician focus groups and limited-scale experimentation (Aikin et al. 2004, Kravitz et al. 2005, Kravitz et al. 2003, Mintzes et al. 2003, Paterniti et al. 2010, Tentler et al. 2008). Venkataraman and Stremersch (2007) quantitatively estimated the positive effect of drug requests on prescriptions by analyzing behavioral data from more than 2,000 physicians across the United States.

Because of the positive effect drug requests may have on prescriptions, there exists great debate on the extent to which patient requests for drugs by brand name are triggered by direct-toconsumer advertising (DTCA) by pharmaceutical manufacturers, whose spending amounted to \$4.3 billion in 2010 (AdAge 2011).

Prior studies hotly contest DTCA's effect on prescriptions, with some studies claiming that DTCA spending has a large effect on prescriptions (Atherly and Rubin 2009, Bell et al. 1999, Fischer and Albers 2010, Iizuka and Jin 2005, Koch-Laking et al. 2010, Kolsarici and Vakratsas 2010, Ling et al. 2002, Meyerhoefer and Zuvekas 2008, Weissman et al. 2004, Wilkes et al. 2000), while others claim it has no effect, or a very limited one, on brand-level prescriptions (Calabro 2003, Calfee et al. 2002, Donohue and Berndt 2004, Manchanda et al. 
2008, Rosenthal et al. 2003, Zachry et al. 2002). Kremer et al. (2008), in a large meta-analysis examining the effectiveness of pharmaceutical promotional expenditures, even find that DTCA has a negative effect on prescriptions in the fields of skin disease, neurology and psychiatry.

Most studies investigating the effect of DTCA on prescriptions forgo the study of drug requests as a mediator, although such mediation is often implied. Some of these studies have focused on other possible mechanisms, aside from patient requests, that might influence the effect of DTCA on prescriptions. One mechanism, suggested by several studies is through overall category size. These studies focus on the 'market expanding' effect of DTCA and its role as a trigger for physician visits that do not affect the choice of a specific brand (Aikin et al. 2004, Brekke and Kuhn 2006, Cantor 2010, Hosken and Wendling 2009, Liu and Gupta 2011). Another suggested mechanism for the effect of DTCA on prescriptions is through patients' price sensitivity (Amaldoss and He 2009, Meyerhoefer and Zuvekas 2008). Amaldoss and He (2009), for instance, suggest that DTCA for branded drugs can help pharmaceutical companies build goodwill among consumers that decreases their price sensitivity leading to higher profits for these companies. Finally, increased patient compliance with the treatment regime was also investigated as a possible mediator through which DTCA can affect prescriptions (Wosinska 2005).

Studies that focus on the extent to which patient requests by brand name are triggered by DTCA are rare and inconclusive. Mintzes et al. (2003) find, using a patient survey, a higher request rate among respondents in Sacramento than among respondents in Vancouver, a difference the researchers attributed to higher DTCA exposure (despite an $87 \%$ cross-border exposure rate in Vancouver). Liu and Gupta (2011) find a positive effect of DTCA on the number of doctor visits in the U.S. The FDA reports that $4 \%$ of patients visit their physicians 
with the primary purpose of asking about an advertised drug (Aikin et al. 2004). Drug requests may also be triggered by sources other than DTCA, such as the available information in the media or on the Internet, and word-of-mouth among patients and between patients and their friends, colleagues or families (Macias and Lewis 2003, Mack 2009, McKillen 2002, Rama and Singh 2009). Parnes et al. (2009) found a similar request rate across categories that had "been advertised in the last few years" versus categories that had not. Weiss et al. (1996) observed an increase in drug requests even in countries that do not allow DTCA.

Physicians also show high heterogeneity in request accommodation behavior, which is left unexplained by prior research (Venkataraman and Stremersch 2007). One explanatory factor may lie in physicians' specialty, because joint decision-making between patients and specialists is less common than joint decision-making between patients and general practitioners (Ding and Eliashberg 2008). Other explanatory factors may be patient socio-demographic characteristics, because of their possible association with the variation in physicians' empathy and tolerance for participatory behavior of patients. For instance, physicians have been shown to be more dominant and less participatory when dealing with older or Black patients, than when dealing with younger or White patients (e.g. Cooper-Patrick et al. 1999, Kaplan et al. 1995, Street and Buller 1988). Public policy shows a high interest in socio-demographic variation in medical treatment (Armitage et al. 1979, Broyles et al. 1999, Hildebrand and Van Kerm 2009, Sehili et al. 2004, Steingart 1991). Race is among the most controversial sources of such sociodemographic variation (Ayanian and Epstein 1991, Bowser 2001, Cohen et al. 2010, Hannan et al. 1991, Hannan et al. 1999, Lillie-Blanton et al. 2000, McKinlay 1996, Peterson et al. 1997, Sonel et al. 2005, Todd et al. 1993, Van Ryn and Burke 2000, Ventres and Gordon 1990, Wenneker and Epstein 1989, Werner et al. 2005). 
The contribution the present paper aims to make is threefold. First, this paper is the first to introduce a model that examines the full chain linking DTCA, drug requests by brand name and prescriptions. Second, it is the first to uncover regional variation across the United States over the elements of the chain. This regional variation is, in turn, explained by the regions' socio-demographic characteristics, and more specifically the race decomposition of the region population, after controlling for income, education, age, gender and urbanization. Third, this paper uncovers differences between specialists and primary care physicians in elements of the DTCA-requests-prescriptions chain. These contributions lead to unique and novel insights that are of relevance to companies and public policy makers.

We have combined three different databases for this study. The first database contains the number of prescriptions, the number of drug requests and the number of detailing visits for branded drugs in the statin category for a panel of U.S. physicians, including the ZIP code in which each practice is located. The second database contains monthly national and local DTCA expenditures for each investigated brand at the Designated Market Area (DMA) level. The third database, from the U.S. Census, contains the socio-demographic characteristics of the 5-digit U.S. ZIP codes. The integrated database contains 142,180 prescriptions for 2,294 physicians over a period of 14 months, spanning 1,854 ZIP codes in 193 DMAs. In addition to these three data sets, we have also obtained and visually inspected all ads (TV and magazine) for the analyzed brands in the investigated time period, as provided to us by Kantar Media.

We specify a system of four equations, at the physician-brand-time level, which we estimate simultaneously. The four equations explain: (1) the monthly number of prescriptions a physician writes, (2) the monthly number of drug requests a physician receives from patients, (3) the monthly number of detailing visits a physician receives from the manufacturer of each drug, 
and (4) the DTCA spending on each drug in the DMA the physician is located in. This system accounts for the endogeneity of patient requests, detailing and DTCA. In order to uncover spatial variation, in terms of socio-demographics, and variation across primary care physicians and specialists, we employ a hierarchical specification for the physician-level model parameters. In addition, using a simulated patient-physician-level dataset, we show that this model can recover patient-level effects, despite being estimated on physician-level and DMA-level data. We demonstrate the robustness of our main findings regarding the regional variation, in terms of socio-demographics, by carrying out a survey of 6,635 U.S. patients dispersed across the United States.

The findings from our study that are new to the literature are as follows. First, we document and identify sources of the large heterogeneity we find in the influence of DTCA both on requests and prescriptions. For instance, we find that DTCA is less important as a driver of drug requests in areas with a higher proportion of minorities (Blacks and Hispanics) than in areas with a lower proportion of minorities. Overall, we find that while there are areas, characterized by a specific socio-demographic make-up, in which higher spending on DTCA translates into more drug requests by brand name, this is not the case in the average DMA, and that the mean effect of DTCA on requests is very small and negative. Second, we find that drug requests, especially to primary care physicians and, to a lesser extent, to specialists, have a significant influence on brand prescriptions, and that the heterogeneity in physicians' tendency to accommodate requests can again be explained by socio-demographic variation across regions. Most controversial is that drug requests by brand name in regions with higher percentages of Blacks and Hispanics translate into fewer prescriptions of that brand as compared to regions with lower percentages of Blacks and Hispanics (i.e., regions with higher percentages of Whites). In 
the long run and on average, each drug request by brand name that a physician receives leads that physician to write 1.69 prescriptions for the requested drug.

As to control variables, we find, in line with previous studies, a positive effect of detailing visits on prescriptions. The average long-run effect of a detailing visit is 0.85 prescriptions. As a detailing visit typically covers three brands, we assume a cost per detailing visit at the brand level to be equal to $\$ 50$ and subsequently obtain an average return on investment (ROI) of detailing equal to 1.51 (i.e., each $\$ 1$ cost of detailing at the brand level generates $\$ 1.51$ in prescriptions at the brand level). The main determinants of local DTCA spending are the number of households owning a television set and the level of competitive spending.

Our findings cast doubt over the extent to which pharmaceutical firms can trigger patient drug requests with DTCA, as it was implemented by the specific manufacturers covered by our data. Recently, communication practices of firms have started shifting to unbranded drug ads (Mundy 2008, Wang 2008). Such ads may relieve the negative effects of mentioning the side effects of a drug, a practice mandated by the FDA if the drug name is mentioned, and which may hinder information processing by consumers. In the future, firms are likely to increasingly shift also to digital and social media, which may prove to be more effective in triggering drug requests by brand name in specific socio-demographic classes. Given the much stronger effect of a drug request on prescriptions, compared to the effect of a detailing visit (long-run effect of $1.69 \mathrm{vs}$. 0.85 , respectively), pharmaceutical firms are likely to continue to develop ways of reaching patients. Towards this effort, our model and results suggest that firms should adopt targeting policies that exploit the spatial patterns according to socio-demographic profile we find in both 
drug request responsiveness to DTCA and physician prescription responsiveness to patient drug requests.

This paper is organized as follows. In the second section, we present the data used for the estimation of our model. In the subsequent sections, we develop our model and describe our estimation procedure. Next, we present the estimation results and a robustness analysis for our findings. We then summarize the implications of our findings for managers and policy makers. In the final section, we discuss future research opportunities.

\section{Data}

We study the statin category in the U.S. from June 2002 to July 2003, a period during which the category consisted only of relatively mature drugs. We integrated three datasets for our empirical analysis, covering 142,180 prescriptions for 2,294 physicians over a 14-month period, spanning 1,854 ZIP codes in 193 DMAs.

The first dataset includes physician-level (subscript $p$ ) panel data that contain monthly (subscript $t$ ), brand-specific (subscript $j$ ) information on the total number of prescriptions written $\left(R x_{p j t}\right)$, the total number of patient drug requests ${ }^{2}\left(R e q_{p j t}\right)$, and the total number of detailing visits $\left(\operatorname{Det}_{p j t}\right)$. This information is recorded via a personal digital assistant (PDA) after each interaction with a patient or a sales representative for a given brand and is therefore unlikely to show underreporting (e.g. because of lack of salience in memory of such interactions). While we cannot reveal the data provider, the provider is contracted by many global pharmaceutical companies as a main provider for physician-level data.

\footnotetext{
${ }^{2}$ Total number of prescriptions includes both new prescriptions and refills. Below, we report a model with new prescriptions only, as our data identifies both separately. Total number of requests includes both requests to start therapy of a drug by brand name as requests to continue therapy of a drug by brand name. Our data does not identify both separately, so we cannot run separate models.
} 
The data also contain the 5-digit ZIP code of each physician's practice and indicate whether the physician is a primary care physician or a specialist. For our empirical analysis, we calibrate the model on physician-level data for the three most prescribed brands, which cumulatively account for $73 \%$ of the category volume. Doing so allows us to reduce the computational complexity and resources needed for our estimation without sacrificing the generalizability of our findings. In the robustness section, we relax this constraint and estimate our model on the five largest brands.

The second dataset contains monthly national and local DTCA expenditures in the DMA in which each physician's practice is located, for each brand in the category, obtained from Kantar Media (previously TNS Media Intelligence), and denoted as DTCA $A_{p j t}$. DMAs are large, and each one contains slightly more than 200 ZIP codes on average. Thus, we may assume that people live in the same areas as the physician practices they visit. On average, over the investigated time frame, the local DTCA expenditures for the three analyzed brands account for $6.4 \%$ of the national DTCA expenditures for these brands. The mean monthly local DTCA expenditures for a given DMA in our sample are $\$ 5,077$. The variation of monthly local DTCA expenditures across DMAs (for the entire time period) is larger than the variation of monthly local DTCA expenditures across months (for all DMAs) (std. of $\$ 15,228$ vs. $\$ 7,306$ for the mean monthly expenditures across DMAs and months respectively).

Figure 1 displays the evolution of DTCA spending (dashed lines) and the mean number of requests (solid lines) for each of the three brands we analyze over the observation period. We find that in our investigated timeframe the mean number of requests is relatively stable, whereas DTCA spending is comparatively volatile. In addition, the pattern across brands in DTCA 
spending does not seem to visually match the pattern across brands in the number of drug requests.

Figure 1. DTCA Spending and the Number of Requests over Time and Brands

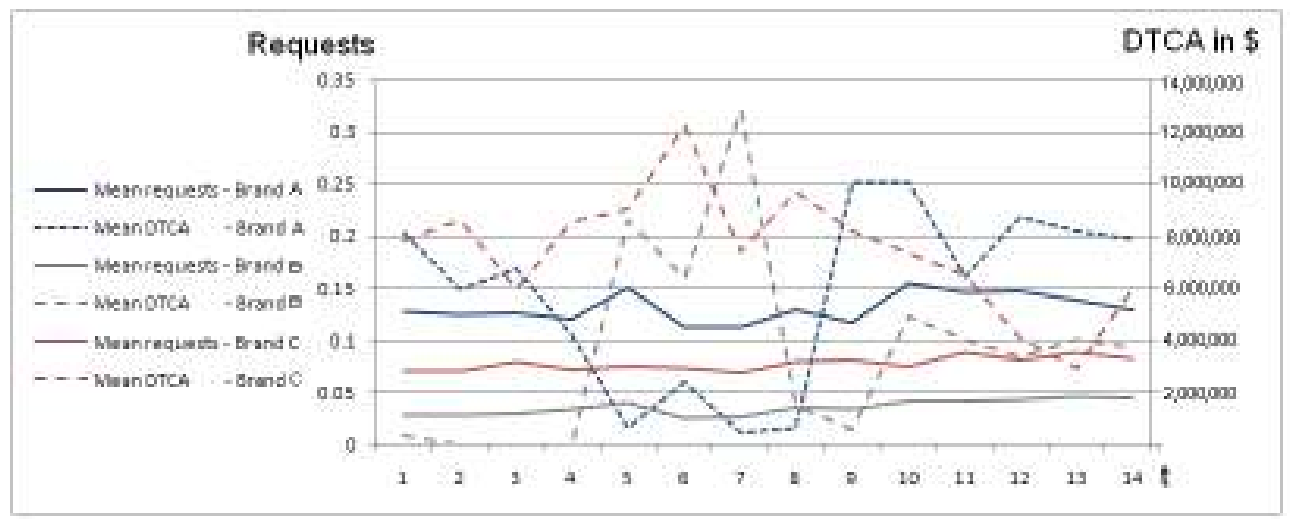

Figure 2 displays the distribution of DTCA spending across different media channels for the three brands we focus on. While Brands A and C divide their DTCA expenditures between television and magazines/newspapers, Brand B spends almost exclusively on magazine/newspaper advertising.

Figure 2. DTCA Expenditures among the Media Channels

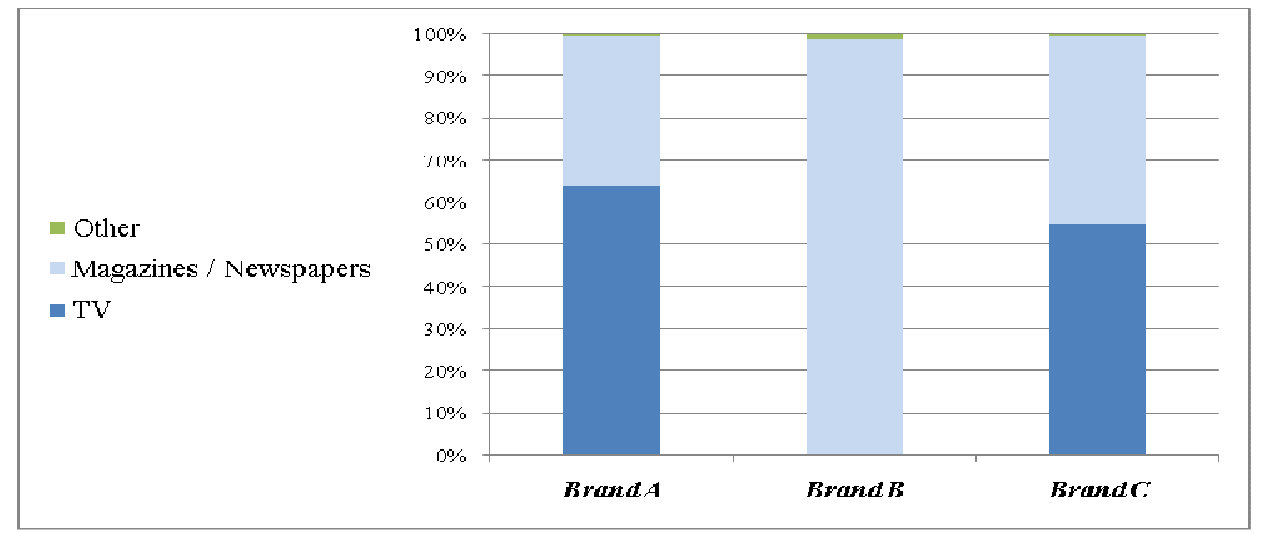

The third dataset contains the 2000 U.S. Census data on the following demographic characteristics of all U.S. ZIP codes, which we aggregated to the DMA level by calculating a weighted (according to the population size of the ZIP code) average: 
- Race: The racial mix of the population in the DMA of the physician, as operationalized by three variables: PerBlack ${ }_{p}$ (percentage of population that is Black), PerHisp $p$ (percentage of population that is Hispanic), and PerAsian $_{p}$ (percentage of population that is Asian) ${ }^{3}$.

- Gender: The gender composition of the population in the DMA of the physician, as operationalized by the percentage of the population that is male, PerMale $_{p}$.

- Age: The age composition of the population in the DMA of the physician, as operationalized by the percentage of the population aged 40 and over, PerOver $40_{p}$.

- Income-Education: We collapse income (median income among the households in the physician's DMA) and education (percentage of population in the physician's DMA older than 25 with one year or more of college education) into one factor to minimize collinearity. Both education and income have a high factor loading $(=0.93)$, and the factor explains $86 \%$ of the variance of the two constituent variables. We denote this factor IncEdu_F $F_{p}$.

- Urbanization: The degree to which the physician's DMA is urban, rather than rural, as the percentage of the population that is located within an urban area, PerUrban . $_{\text {. }}$

We also include physician specialty, $\operatorname{Spec}_{p}(0=$ primary care physician; $1=$ cardiologist $)$. Table 1 provides Pearson correlations between all variables and their mean and standard deviation.

\section{Model}

Our model consists of a system of four equations estimated simultaneously. First, we present the prescriptions equation, after which we turn to the equations for drug requests, detailing and

DTCA. We end with the estimation procedure.

\footnotetext{
${ }^{3}$ In the decennial census 'Hispanic or Latino' people are those who identify with the terms 'Spanish', 'Hispanic', or 'Latino' as well as people whose origins are from Spain, the Spanish-speaking countries of Central or South America, the Dominican Republic, or people identifying themselves generally as Spanish, Spanish-American, Hispanic, Hispano, Latino, and so on. 'Black' are defined as people who have origins in any of the Black racial groups of Africa, including people who indicate their race as Black, African-American or Negro or provide written entries such as Kenyan, Nigerian, or Haitian. 'Asians' are defined as people who indicate having origins in the Far East, Southeast Asia, or the Indian subcontinent, including Cambodia, China, India, Japan, Korea, Malaysia, Pakistan, the Philippine Islands, Thailand, and Vietnam.
} 
Table 1. Descriptive Statistics and Correlation Table

\begin{tabular}{|c|c|c|c|c|c|c|c|c|c|c|c|c|}
\hline & \multicolumn{4}{|c|}{ Dependent Variables } & \multirow{2}{*}{ 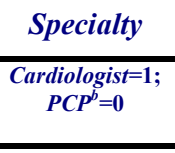 } & \multicolumn{7}{|c|}{ Socio-Demographic Characteristics of Regions } \\
\hline & $\begin{array}{c}\text { Mean } \\
\text { Prescriptions }^{a}\end{array}$ & $\begin{array}{l}\text { Mean Drug } \\
\text { Requests }^{a}\end{array}$ & $\begin{array}{c}\text { Mean } \\
\text { Detailing } \\
\text { Visits }^{a} \\
\end{array}$ & $\begin{array}{c}\text { Mean } \\
\text { DTCA } \\
\text { Expenses }^{a} \\
\end{array}$ & & $\begin{array}{l}\text { Percent } \\
\text { Black }\end{array}$ & $\begin{array}{l}\text { Percent } \\
\text { Hispanic }\end{array}$ & $\begin{array}{l}\text { Percent } \\
\text { Asian }\end{array}$ & $I n c E d u_{-} F$ & $\begin{array}{l}\text { Percent } \\
\text { Male }\end{array}$ & $\begin{array}{l}\text { Percent } \\
\text { Over } 40\end{array}$ & $\begin{array}{c}\text { Percent } \\
\text { Urban }\end{array}$ \\
\hline Mean Drug Requests ${ }^{a}$ & 0.05 & & & & & & & & & & & \\
\hline Mean Detailing Visits ${ }^{a}$ & 0.59 & 0.08 & & & & & & & & & & \\
\hline Mean DTCA Expenses ${ }^{a}$ & 0.09 & 0.02 & 0.05 & & & & & & & & & \\
\hline $\begin{array}{l}\text { Specialty } \\
\left(\text { Cardiologist }=1 ; P C P^{b}=0\right)\end{array}$ & 0.14 & 0.08 & 0.03 & 0.09 & & & & & & & & \\
\hline Percent Black & 0.08 & 0.00 & 0.11 & 0.22 & 0.02 & & & & & & & \\
\hline Percent Hispanic & 0.00 & 0.04 & 0.01 & 0.32 & 0.10 & -0.19 & & & & & & \\
\hline Percent Asian & 0.01 & 0.03 & -0.01 & 0.42 & 0.09 & -0.07 & 0.45 & & & & & \\
\hline IncEdu_F & 0.05 & 0.03 & 0.00 & 0.57 & 0.05 & 0.02 & 0.17 & 0.50 & & & & \\
\hline Percent Male & -0.09 & -0.01 & -0.07 & -0.21 & -0.04 & -0.46 & 0.33 & 0.26 & 0.04 & & & \\
\hline Percent Over 40 & 0.04 & 0.01 & 0.01 & -0.21 & 0.01 & -0.12 & -0.47 & -0.35 & -0.19 & -0.48 & & \\
\hline Percent Urban & 0.06 & 0.04 & -0.01 & 0.65 & 0.10 & 0.03 & 0.56 & 0.54 & 0.69 & 0.06 & -0.28 & \\
\hline Mean & 4.4 & 0.24 & 1.56 & 5,593 & 0.07 & 0.13 & 0.11 & 0.03 & 0.46 & 0.49 & 0.43 & 0.77 \\
\hline Std. & 6.6 & 1.54 & 2.53 & 9.95 & 0.25 & 0.10 & 0.13 & 0.03 & 0.95 & 0.01 & 0.04 & 0.17 \\
\hline
\end{tabular}




\subsection{Prescriptions Equation}

We specify a conditional negative binomial distribution (NBD) model for the distribution of prescriptions written, given patient drug requests, while controlling for detailing; DTCA; lagged DTCA, which captures possible carry-over effects of advertising; competitive prescriptions $\left(C o m p R x_{p j t}\right)$; competitive requests $\left(C_{0 m p R e} q_{p j t}\right)$; the lagged mean prescriptions in the DMA (meanRxDMA $\left.A_{p j t-1}\right)$, which captures the effect of word-of-mouth for a drug among physicians in a DMA; and lagged prescriptions, which captures inertia in physician prescription behavior. The NBD model enables us to accommodate overdispersion in the data. An NBD distribution with mean $\lambda_{p j t}^{R X}$ and overdispersion parameter $\alpha^{R X}$ is represented by:

(1) $\quad \operatorname{Pr}\left(R X_{p j t}=k \mid \lambda_{p j t}^{R X}, \alpha^{R X}\right)=\frac{\Gamma\left(\alpha^{R X}+k\right)}{\Gamma\left(\alpha^{R X}\right) \Gamma(k+1)}\left(\frac{\alpha^{R X}}{\alpha^{R X}+\lambda_{p j t}^{R X}}\right)^{\alpha^{R X}}\left(\frac{\lambda_{p j t}^{R X}}{\alpha^{R X}+\lambda_{p j t}^{R X}}\right)^{k}$

We specify the $\log$ of the mean of the conditional distribution as linear in the parameters ${ }^{4}$.

(2)

$$
\begin{aligned}
\ln \left(\lambda_{p j t}^{R x}\right) & \left.=\beta_{0 p j}+\beta_{1 p} \ln \left(\operatorname{Req}_{p j t}+1\right)+\beta_{2 p} \ln \left(\text { Det }_{p j t}+1\right)\right)+\beta_{3 p} \ln \left(D T C A_{p j t}+1\right) \\
& +\beta_{4 p} \ln \left(D T C A_{p j t-1}+1\right)+\beta_{5 p} \ln \left(\operatorname{CompRx}_{p j t}+1\right)+\beta_{6 p} \ln \left(\operatorname{CompReq}_{p j t}+1\right) \\
& +\beta_{7 p} \ln \left(\text { meanRxDMA }_{p j t-1}+1\right)+\beta_{8 p} \ln \left(R x_{p j t-1}+1\right)+\xi_{p j t}^{R x}
\end{aligned}
$$

We account for different baseline prescription levels for all brands via a brand-specific intercept $\beta_{0 p j}$. Next, we decompose the main parameters of interest $\left(\beta_{0 p j}, \beta_{1 p}, \beta_{2 p}\right.$ and $\left.\beta_{3 p}\right)$ according to physician specialty, as well as socio-demographic characteristics of the physician DMA to uncover spatial variation, in the following manner:

$$
\beta_{0 p j}=\left(\begin{array}{ll}
\omega_{00 j} & +\omega_{01} \text { Spec }_{p} \\
+\omega_{02} \text { PerBlack }_{p}+\omega_{03} \text { PerHisp }_{p} & +\omega_{04} \text { PerAsian }_{p} \\
+\omega_{05} \text { IncEdu_F }_{-} F_{p}+\omega_{06} \text { PerMale }_{p} & +\omega_{07} \text { PerOver }_{0_{p}} \\
+\omega_{08} \text { PerUrban }_{p}
\end{array}\right)+v_{0 p}
$$

\footnotetext{
${ }^{4}$ Note that due to estimation complexity, we allow for heterogeneity across physicians in all first-level parameters, and across brands in all base-level effects, yet assume all response parameters to be homogenous across brands.
} 


$$
\begin{aligned}
& \beta_{k p}=\left(\begin{array}{lll}
\omega_{k 0} & +\omega_{k 1} \text { Spec }_{p} & \\
+\omega_{k 2} \text { PerBlack }_{p} & +\omega_{k 3} \text { PerHisp }_{p} & +\omega_{k 4} \text { PerAsian }_{p} \\
+\omega_{k 5} \text { IncEdu_F }_{p} & +\omega_{k 6} \text { PerMale }_{p} & +\omega_{k 7} \text { PerOver }_{4} 0_{p} \\
+\omega_{k 8} \text { PerUrban }_{p} &
\end{array} \quad, \text { with } \mathrm{k}=1,2,3\right. \\
& v_{0-3 p} \sim \operatorname{MVN}\left(0, \Sigma_{\beta}\right)
\end{aligned}
$$

\subsection{Drug Requests Equation}

We construct a conditional NBD model for the distribution of the number of monthly drug requests a physician receives for a brand, given DTCA, lagged DTCA and lagged prescriptions. Lagged prescriptions capture word-of-mouth among patients within a physician's practice and also capture carry-over effects of the independent variables in the prescriptions equation, such as requests, and detailing. We specify the log of the mean of the conditional distribution $\left(\lambda_{p j t}^{R e q}\right)$ :

(6) $\ln \left(\lambda_{p j t}^{R e q}\right)=\alpha_{0 p j}+\alpha_{1 p} \ln \left(D T C A_{p j t}+1\right)+\alpha_{2 p} \ln \left(D T C A_{p j t-1}+1\right)+\alpha_{3 p} \ln \left(R x_{p j t-1}+1\right)+\xi_{p j t}^{R e q}$

Note that we include lagged DTCA in our request equation in order to explicitly account for a carry-over effect of DTCA also in cases where DTCA does not have a direct effect on prescriptions. Thus, the overall effect of lagged DTCA on requests is given by the three parameters, $\alpha_{2 p}, \alpha_{3 p}$ and $\beta_{3 p}$. The parameter $\alpha_{0 p j}$ represents a physician-brand-specific intercept for the number of drug requests, which we specify in a hierarchical manner. First, we allow physicians' responsiveness to drug requests (in terms of prescribing) to affect the number of received drug requests by including $\beta_{1 p}$ (see Equation 2), as a variable determining $\alpha_{0 p j}$ in the second-level hierarchy specification (see Equation 7$)^{5}$. As before, we include physician specialty, as well as socio-demographic characteristics of the DMA to uncover spatial variation, in the following manner:

\footnotetext{
${ }^{5} \mathrm{We}$ assume that in our sample patients are no longer learning about their physicians' request accommodation behavior. Rather, we assume that the patient-physician allocations are based on an equilibrium resulting from patients' long-term choices regarding their physicians.
} 


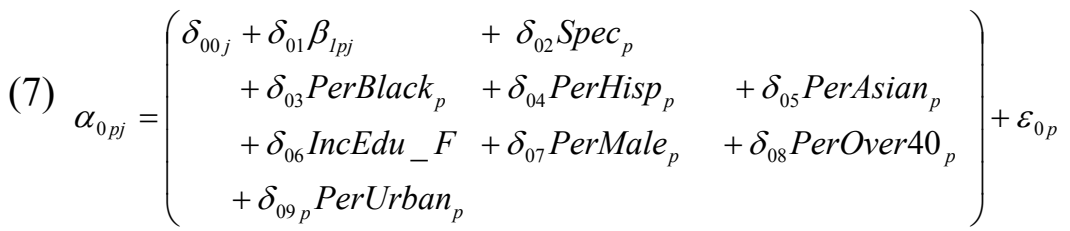

To uncover how specialty and spatial variation influence the effect of contemporaneous DTCA on the number of patient requests a physician receives, we also define a hierarchical structure for $\alpha_{1 p}$ :

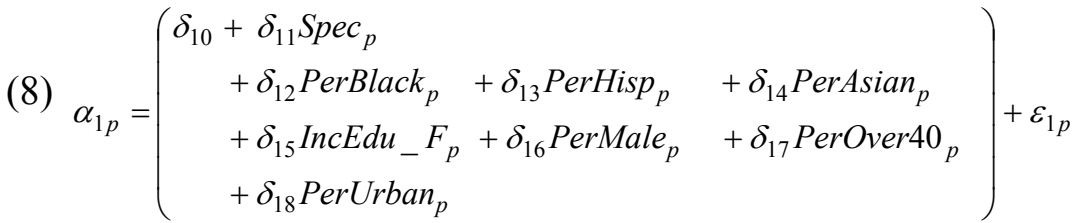

Where, $\varepsilon_{0-1 p} \sim \operatorname{MVN}\left(0, \Sigma_{\alpha}\right)$

\subsection{Detailing and DTCA Equation}

To address the endogeneity of detailing and DTCA in the prescriptions and requests equations, we implement a limited-information approach wherein we explicitly model the detailing and DTCA data-generating processes (see Section 3.5 below for a discussion regarding our approach to deal with endogeneity). Accordingly, we model both detailing and DTCA as non-random variables. The detailing equation is specified as follows:

(9) $\ln \left(\lambda_{p j t}^{D e t}\right)=\gamma_{0 p j}+\gamma_{1 p} \ln \left(R x_{p j t-1}+1\right)+\gamma_{2 p} \ln \left(\operatorname{CompDet}_{p j t-1}+1\right)+\gamma_{3 p} \ln \left(\operatorname{Det}_{p j t-1}+1\right)+\xi_{p j t}^{\text {Det }}$

We expect that pharmaceutical companies set the number of detailing visits according to the number of prescriptions written by the physician for the brand in the previous period (captured by $\gamma_{1 p}$ ), the competitive details the physician received in the previous period, CompDet $_{p j t-1}$ (captured by $\gamma_{2 p}$ ), and the physician's responsiveness to detailing, $\beta_{2 p}$ (captured by $\rho_{01}$ ), in the specification of the parameter $\gamma_{0 p j}$, in Equation (10) below (Manchanda et al. 2005). In addition, we allow for inertia in the number of detailing visits a physician receives by including 
lagged detailing in Equation (9). The parameter $\gamma_{0 p j}$ represents a physician-brand intercept for the number of detailing visits, which we specify in a hierarchical manner, as follows:

$$
\gamma_{0 p j}=\rho_{00 j}+\rho_{01} \beta_{2 p}+\pi_{0 p}
$$

Where, $\pi_{p} \sim N\left(0, \Sigma_{\gamma}\right)$

Note that in order to tackle potential endogeneity in physician-specific detailing in Equation (2), we included non-marketing response drivers in Equations (9) and (10) by explicitly accounting for the number of prescriptions written by the physician, as well as responsiveness of the physician to detailing.

We specify the DTCA equation, as follows:

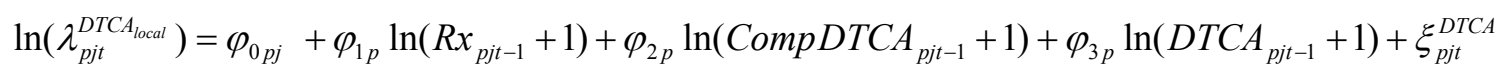

We specify the parameter $\varphi_{0 \mathrm{p} j}$ in a hierarchical manner, as follows:

$$
\varphi_{0 p j}=\mu_{00 j}+\mu_{01} \alpha_{l p}+\mu_{02} \beta_{l p}+\mu_{03} \beta_{3 p}+\mu_{04} H H_{-} T V_{P}+\varsigma_{0 p}
$$

Where, $\varsigma_{p} \sim N\left(0, \Sigma_{\varphi}\right)$

We expect that pharmaceutical companies set the DTCA spending in a physician's region as a function of the volume of written prescriptions in the previous period, the DTCA spending of competitors in the previous period, CompDTC $A_{p j t-1}$, and the inertia in DTCA spending. We further specify the base level of DTCA spending in a given physician's region as a function of responsiveness of requests to DTCA $\left(\alpha_{1 p}\right)$, the responsiveness of prescriptions to requests $\left(\beta_{1 p}\right)$, the responsiveness of prescriptions to DTCA $\left(\beta_{3 p}\right)$ and the number of households in the region with a television set.

Note, again, that in order to account for potential endogeneity in DTCA spending, we included non-marketing response drivers in Equations (11) and (12). For instance, $H H_{-} T V_{p}$ in 
the specification of $\varphi_{0 \mathrm{p} j}$ captures the effect of market size on DTCA expense allocations across DMAs.

In all four equations (i.e., prescriptions, requests, detailing and DTCA), there could be other elements (such as the release of a clinical study on a given drug) that affect the investigated variables but are unobserved by the researcher. Failure to account for these factors leads to an endogeneity problem (Villas-Boas and Winer 1999). In order to overcome this problem, we incorporate brand-specific periodic demand shocks to all equations through brand-specific timevarying factors via the stochastic error terms $\xi_{p j t}^{R X}, \xi_{p j t}^{R e q}, \xi_{p j t}^{D e t}$ and $\xi_{p j t}^{D T C A}$. We specify a multivariate normal distribution for the four error terms: $\left[\begin{array}{l}\xi_{p j t}^{R x} \\ \xi_{p j t}^{R e q} \\ \xi_{p j t}^{D e t} \\ \xi_{p j t}^{D T C A}\end{array}\right] \sim M V N\left(\left[\begin{array}{l}0 \\ \vdots \\ 0\end{array}\right], S_{\xi}\right)$.

The distribution of the errors across the four equations is brand-specific. In our estimation procedure the errors come from a multivariate-normal distribution with a mean of zero and a 12 by 12 variance-covariance matrix.

\subsection{Estimation}

All four equations are estimated simultaneously as a system. In addition to correlated error terms across the four equations, there are four elements connecting the equations. First, $\beta_{1 p}$ in Equation (2) appears in the structure of $\alpha_{0 p j}$ (see Equation 7) and in the structure of $\varphi_{0 \mathrm{p} j}$ (see Equation 12). Second, $\beta_{2 p}$ in Equation (2) appears in the structure of $\gamma_{0 p j}$ (see Equation 10). Third, $\beta_{3 p}$ in Equation (2) appears in the structure of $\varphi_{0 p j}$ (see Equation 12). Fourth, $\alpha_{1 p}$ in Equation (6) appears in the structure of $\varphi_{0 p j}$ (see Equation 12). That is, we include the physicians' responsiveness to requests as a determinant of the number of requests; the 
responsiveness of prescriptions to detailing as a determinant of detailing; and the responsiveness of prescriptions to requests, the responsiveness of prescriptions to DTCA and the responsiveness of requests to DTCA as determinants for DTCA spending. These links between the four equations, together with the simultaneous estimation of the entire system, allow us to overcome possible biases due to endogeneity of requests, detailing and DTCA budget allocations.

For the estimation of the overdispersion parameters of the four NBD equations $\left(\alpha^{R X}, \alpha^{\operatorname{Re} q}, \alpha^{D e t}\right.$, and $\left.\alpha^{D T C A}\right)$ we followed the typical assumption in the literature, according to which heterogeneity is modeled in the location parameter. This assumption allows both the mean and the variance of the distribution to vary, given that mean and variance are related.

The likelihood function is therefore:

$$
l\left(\left\{\mathrm{~B}, \xi_{p j t}^{R X}, \Omega, \mathrm{A}, \xi_{p j t}^{R e q}, \Delta, \Gamma, \xi_{p j t}^{D e t}, \mathrm{P}, \Phi, \xi_{p j t}^{D T C A}, \Lambda, \mathrm{O}\right\}\right)=\prod_{p, j, t}\left[\begin{array}{l}
\operatorname{Pr}\left(R X_{p j t} \mid \mathrm{B}, \xi_{p j t}^{R X}, \Omega, \alpha^{R x}\right) \\
\times \operatorname{Pr}\left(R e q_{p j t} \mid \mathrm{A}, \beta_{1 p}, \xi_{p e q}^{R e q}, \Delta, \alpha^{\mathrm{Req}}\right) \\
\times \operatorname{Pr}\left(D e t_{p j t} \mid \Gamma, \beta_{2 p}, \xi_{p j t}^{D e t}, \mathrm{P}, \alpha^{D e t}\right) \\
\times \operatorname{Pr}\left(D T C A_{p j t} \mid \Phi, \beta_{1 p}, \beta_{3 p}, \alpha_{1 p}, \xi_{p j t}^{D T C A}, \Lambda, \alpha^{D T C A}\right)
\end{array}\right]
$$

where $\{\mathrm{B}, \mathrm{A}, \Gamma, \Phi\}$ represent the first-layer parameters, $\{\Omega, \Delta, \mathrm{P}, \Lambda\}$ represent the parameters in the second layers of Equations (2), (6), (9) and (11), respectively, and $O$ represents a vector of four overdispersion parameters. For the estimation, we used the Hierarchical Bayes Markov Chain Monte Carlo (HB MCMC) estimation procedure. Details regarding the estimation are presented in Web Appendix A.

\subsection{Accounting for Endogeneity}

Extant research has repeatedly demonstrated that the failure to properly account for unmeasured brand characteristics (UBCs) that affect consumer choices as well as firms' decisions (due to their influence on choices and hence on demand) results in two main outcomes. The first possible outcome is an endogeneity bias, which yields erroneous estimates of the mean effect of 
marketing-mix variables (Berry 1994; Villas-Boas and Winer 1999). The second outcome is overstated variances in the estimated preference heterogeneity distribution and marketing-mix sensitivities (Chintagunta et al. 2005). These two concerns hold both while estimating demand models with aggregate and individual-level panel data (like the one used in the current study).

Several alternatives have been proposed to address the aforementioned UBC problems. The first alternative (Alternative \#1) is a full-information approach to calibrate a structural demand model with or without a supply-side model. Studies in this stream usually rely on aggregate data and follow a Berry, Levinsohn and Pakes (1995) style GMM estimation framework. When a supply-side is specified, the demand and supply-side models are separately estimated and the UBCs and supply-side unobservables are assumed to be uncorrelated with a set of exogenous instruments (Nevo 2001; Sudhir 2001; Chintagunta et al. 2005). By separately estimating the demand and supply-side models, supply-side misspecification does not impact the inference of the demand model. One also does not need to make any distributional assumptions on UBCs or supply-side cost shocks. These advantages come with some risk. Specifically, this approach cannot accommodate correlations between UBCs and supply-side cost shocks. The approach is also predicated on being able to obtain good quality instrumental variables.

The second alternative (Alternative \#2) is to formally model the joint distribution of the endogenous marketing-mix elements and demand-side choices using maximum likelihood $(M L)$ methods while accounting for the correlation between UBCs and supply-side cost shocks. A key advantage of the ML approach is that one can easily integrate out the UBCs and supply-side cost shocks and work with the unconditioned joint likelihood. The approach negates the need to have instrumental variables. Studies that pursue ML methods, however, differ in the way the supply side is modeled. Some studies in this stream, like Alternative \#1, undertake a full-information 
approach where the data-generating process for the endogenous supply-side variables is modeled structurally as the equilibrium outcome of a game played between competing firms (Villas-Boas and Zhao 2001). A key advantage of the full-information approach is that by recovering the structural parameters of the demand and supply-side, the researcher can use the recovered parameter estimates to conduct policy-relevant counterfactuals. However, these advantages come at a risk. For example, misspecification in the mechanism that generates the correlation between the modeled supply-side marketing-mix elements and the UBCs results in biased and inconsistent estimates not only of the parameters in the supply-side variables, but more importantly of the demand parameters (Dube and Chintagunta 2003; Bajari 2003; Chintagunta et al. 2005). Furthermore, the full-information approach is subject to the risk of multiple equilibria (Berry 2003).

In the third alternative (Alternative \#3), like in Alternative \#2, the researcher models the joint distribution of the endogenous marketing-mix elements and demand-side choices using maximum-likelihood (ML) methods. Unlike Alternative \#2, here the researcher uses a limitedinformation approach wherein the supply-side marketing elements are modeled in a reduced form. Like Alternative \#2, here too, correlation between UBCs and supply-side cost shocks are readily accommodated. This is the approach undertaken in the current study. The key advantage of the limited-information approach in the current context is that one does not have to make any assumptions on the nature of conduct between firms or assume that the observed actions are equilibrium outcomes. This does away with the key limitation of the full-information approach of Alternative \#2. Here the supply side is modeled either as linear or non-linear (as in the current study) functions of variables that are uncorrelated with the UBCs and the stochastic components that correlated with the UBCs. The researcher then specifies a joint distribution of the UBCs and 
supply-side random components along with the distribution assumption for consumer heterogeneity (Villas-Boas and Winer 1999; Draganska and Jain 2002). However, since the endogenous supply-side elements enter the demand model non-linearly, one needs to use a transformation of variables to derive the joint likelihood which now includes a Jacobian term in it. Conducting high-dimensional integration of such a complicated likelihood function can be very challenging and present the single biggest computational bottleneck.

Yang et al. (2003) propose a novel hierarchical Bayesian framework to estimate the parameters of the joint likelihood in Alternative \#2 style models. The study leverages MCMC methods that are at the heart of the Bayesian inference procedures tailor-made to compute very high dimensional integrals. In the Bayesian framework, a high-dimension integration boils down to drawing random numbers from standard distributions and evaluating parametric density functions. The computational advantages of the Bayesian approach allow researchers to calibrate demand models with very flexible forms of heterogeneity while still being computationally tractable. Like the classical counterpart, here too, the researcher needs to make distributional assumptions on the correlation between UBCs and supply-side cost shocks.

Manchanda et al. (2005) introduced the hierarchical Bayesian approach to Alternative \#3 style models while accounting for non-randomness in the marketing-mix elements. The estimation approach undertaken in the current study is an extension of the approach outlined in Manchanda et al. (2005). While the Manchanda et al. (2005) study jointly models the physicianspecific prescription and detailing models, the current study jointly models physician-specific prescription, detailing, patient-requests and direct-to-consumer advertising equations, while allowing for non-randomness in detailing, patient requests and direct-to-consumer advertising. 


\section{Results}

\subsection{Model Performance}

Our estimation procedure converged satisfactorily. The Brooks and Gelman diagnostic measure (Brooks and Gelman 1998), over our 115 parameters, is very close to 1, with an average of 1.01, a minimum value of 0.99 , and a maximum value of 1.15 (only two parameters had a value between 1.1 and 1.15, and only one parameter had a value between 0.990 and 0.995$)$. Graphs of parameter estimates across model iterations show satisfactory convergence for all parameters and are available from the authors upon request.

Our model performs well, in comparison to nested benchmark models. First, our model outperforms a system of three equations that excludes drug requests, both as a variable in the prescriptions equation and as a separate equation in the system (out-of-sample RMSPE ${ }^{6}$ for prescriptions of 1.57 (full model) vs. 1.59 (benchmark model 1)). Second, our model outperforms a system of (three) equations that excludes detailing, both as a variable in the prescriptions equation and as a separate equation in the system (out-of-sample RMSPE for prescriptions of 1.57 (full model) vs. 1.59 (benchmark model 2)). Third, our model performs similarly to a system of (three) equations that excludes DTCA, both in the requests and prescriptions equations and as a separate equation in the system. This lack of fit improvement following the inclusion of DTCA further shows that in the observation period, DTCA did not play a large role in requests or prescriptions in this category. Fourth, our model outperforms a

\footnotetext{
${ }^{6}$ For the calculation of the RMSPE (Root Mean Square Prediction Error) we used the hold-out sample of the last three months of data, assuming all model variables are known for these hold-out months. Using a paired $t$-test, we tested whether the square roots of the squared errors for each row in our out-of-sample data obtained by the predictions from our model are significantly different from those obtained by the benchmark models. We find that the differences are significant in all comparisons at a significance level of 0.99 , except for the model that excludes DTCA.
} 
model with homogenous parameters across physicians (out-of-sample RMSPE for prescriptions of 1.57 (full model) vs. 1.70 (benchmark model 4)). Fifth, we also compare our model with a model without a second layer, but with random coefficients, and find that both models show a similar out-of-sample fit, as one would expect. This outcome eases concerns of overfitting, as no additional variance is explained by a model with random coefficients. The estimates of the five nested models are similar - both in sign and in significance level - to the estimates of our full model and can be obtained from the authors upon request.

\subsection{First-Layer Estimates}

Table 2 reports the first-layer estimates of our system of equations. The first column shows the dependent variables of the respective equations, the second column shows the independent variables, and the third column shows the parameter symbols. Column 4 shows the estimated population mean, with its standard deviation across all draws from the posterior distribution in parentheses. Bold numbers for the posterior population mean indicate that zero lies outside the $95 \%$ highest posterior density interval of the population mean (Yang and Allenby 2003$)^{7}$.

Column 5 shows the population standard deviation of each parameter (i.e., the standard deviation of the physician specific parameters). This column provides an indication for the extent of heterogeneity across physicians in a given parameter. Column 6 shows each parameter's posterior probability. The posterior probability refers to the likelihood that the parameter, drawn for our population of physicians, is greater than zero (if the posterior distribution mean is positive) or smaller than zero (if the posterior distribution mean is negative). Thus, a parameter

\footnotetext{
${ }^{7}$ We calculate the probability that zero lies outside of the $95 \%$ highest posterior density interval of the distribution mean. This calculation is based on the standard deviation of the population mean across all draws of that mean in the MCMC procedure. Parameter means for which the zero lies outside of the $95 \%$ highest posterior density interval are marked in bold.
} 
with a positive population mean and a posterior probability of $98 \%$ reflects a case where for $98 \%$ of the posterior distribution the sign for the parameter is above zero. A parameter with a negative population mean and a posterior probability of $98 \%$ reflects a distribution where for $98 \%$ of the distribution the sign for the parameter is below zero.

\subsubsection{DTCA - Requests - Prescriptions}

The mean of the distribution for the main effect of DTCA on drug requests is negative $\left(\alpha_{1 p}=-\right.$ 0.29, std.$=0.07$ ), but this effect shows great heterogeneity across physicians (population standard deviation of 0.72 ). In $66 \%$ of our posterior sample draws, DTCA has a negative effect on the number of drug requests by brand name, while in $34 \%$ of our posterior sample draws DTCA has a positive effect on the number of drug requests by brand name. Looking at the posterior draws for each individual physician, we find that for only $7 \%$ of our population of physicians zero is outside the $90 \%$ posterior interval, with $6 \%$ having negative draws and just $1 \%$ having positive draws. This finding fits the mixed evidence on the extent to which DTCA triggers drug requests by brand name (e.g. Calabro 2003, Parnes 2009, Weiss et al. 1996) and, more generally, on the effect of DTCA on prescriptions (e.g. Kremer et al. 2008).

The carry-over effect of DTCA, both directly in the prescription equation and indirectly in the request equation, and the (main) direct effect of DTCA on the number of prescriptions are negligible $\left(\alpha_{2 p}=-0.01\right.$, std. $=0.05 ; \beta_{3 p}=0.0003$, std. $=0.01 ; \beta_{4 p}=0.01$, std. $\left.=0.01\right)$. Thus, additional DTCA spending does not have a positive effect on a physician's tendency to prescribe the advertised drug, nor does it have a significant carry-over effect in future time periods. This finding fits the descriptive pattern in Figure 1, in which, visually, the pattern across brands in DTCA spending does not match the pattern across brands in the number of drug requests. 
There may be several reasons why we, in this category in this time window, do not find a large and positive effect of DTCA (as in Fischer and Albers 2010, Ling et al. 2002) but instead find small or even negative effects (as in Calfee et al. 2002, Calabro 2003, Donohue and Berndt 2004, Manchanda et al. 2008, Rosenthal et al. 2003, Zachry et al. 2002, Kremer et al. 2008).

Table 2. First-Layer Estimates

\begin{tabular}{|c|c|c|c|c|c|}
\hline Dependent Variable & Independent Variables & $\begin{array}{l}\text { Parameter } \\
\text { Symbols }\end{array}$ & $\begin{array}{c}\text { Population Mean } \\
\text { (Estimate Std.)* }\end{array}$ & $\begin{array}{l}\text { Population } \\
\text { Std. }\end{array}$ & $\begin{array}{c}\text { Posterior } \\
\text { probability }\end{array}$ \\
\hline \multirow{11}{*}{$\begin{array}{l}\text { Number of Prescriptions } \\
\text { Written }\end{array}$} & Intercept (Brand A) & $\beta_{0 p 1}$ & $\begin{array}{l}-1.20 \\
(0.06)\end{array}$ & 1.62 & $77 \%$ \\
\hline & Intercept (Brand B) & $\beta_{0 p 2}$ & $\begin{array}{l}-2.78 \\
(0.06)\end{array}$ & 1.83 & $93 \%$ \\
\hline & Intercept (Brand C) & $\beta_{0 p 3}$ & $\begin{array}{l}-2.01 \\
(0.06)\end{array}$ & 1.81 & $87 \%$ \\
\hline & Drug request & $\beta_{1 p}$ & $\begin{array}{c}1.10 \\
(0.06)\end{array}$ & 1.00 & $86 \%$ \\
\hline & Detailing & $\beta_{2 p}$ & $\begin{array}{c}0.60 \\
(0.02)\end{array}$ & 0.52 & $88 \%$ \\
\hline & $D T C A$ & $\beta_{3 p}$ & $\begin{array}{c}3.03 \mathrm{E}-03 \\
(0.01)\end{array}$ & 0.25 & $50 \%$ \\
\hline & Lag DTCA & $\beta_{4 p}$ & $\begin{array}{c}0.01 \\
(0.01)\end{array}$ & 0.39 & $51 \%$ \\
\hline & Competitive prescriptions & $\beta_{5 p}$ & $\begin{array}{c}0.78 \\
(0.02)\end{array}$ & 0.66 & $88 \%$ \\
\hline & Competitive requests & $\beta_{6 p}$ & $\begin{array}{c}0.01 \\
(0.03)\end{array}$ & 0.60 & $51 \%$ \\
\hline & Lag mean prescriptions in DMA & $\beta_{7 p}$ & $\begin{array}{c}0.02 \\
(0.02)\end{array}$ & 0.26 & $53 \%$ \\
\hline & Lag prescriptions & $\beta_{8 p}$ & $\begin{array}{c}0.27 \\
(0.01)\end{array}$ & 0.36 & $77 \%$ \\
\hline \multirow{6}{*}{$\begin{array}{l}\text { Number of Requests } \\
\text { Received }\end{array}$} & Intercept (Brand A) & $\alpha_{0 p 1}$ & $\begin{array}{l}-5.82 \\
(0.12)\end{array}$ & 3.00 & $97 \%$ \\
\hline & Intercept (Brand B) & $\alpha_{0 p 2}$ & $\begin{array}{l}-7.87 \\
(0.14)\end{array}$ & 3.36 & $99 \%$ \\
\hline & Intercept (Brand C) & $\alpha_{0 p 3}$ & $\begin{array}{l}-6.66 \\
(0.14)\end{array}$ & 3.25 & $98 \%$ \\
\hline & $D T C A$ & $\alpha_{1 p}$ & $\begin{array}{l}-0.29 \\
(0.07)\end{array}$ & 0.72 & $66 \%$ \\
\hline & $\operatorname{Lag} D T C A$ & $\alpha_{2 p}$ & $\begin{array}{l}-0.01 \\
(0.05)\end{array}$ & 0.62 & $50 \%$ \\
\hline & Lag prescriptions & $\alpha_{3 p}$ & $\begin{array}{l}-0.33 \\
(0.04) \\
\end{array}$ & 0.91 & $64 \%$ \\
\hline \multirow{6}{*}{$\begin{array}{l}\text { Number of Detailing Visits } \\
\text { Received }\end{array}$} & Intercept (Brand A) & $\gamma_{0 p 1}$ & $\begin{array}{l}-2.15 \\
(0.05)\end{array}$ & 1.81 & $88 \%$ \\
\hline & Intercept (Brand B) & $\gamma_{0 p 2}$ & $\begin{array}{l}-3.59 \\
(0.07)\end{array}$ & 2.27 & $94 \%$ \\
\hline & Intercept (Brand C) & $\gamma_{0 p 3}$ & $\begin{array}{l}-2.15 \\
(0.05)\end{array}$ & 1.88 & $87 \%$ \\
\hline & Lag prescriptions & $\gamma_{1 p}$ & $\begin{array}{l}0.57 \\
(0.03)\end{array}$ & 0.66 & $81 \%$ \\
\hline & Lag competitive detailing & $\gamma_{2 p}$ & $\begin{array}{c}0.36 \\
(0.02)\end{array}$ & 0.52 & $76 \%$ \\
\hline & Lag detailing & $\gamma_{3 p}$ & $\begin{array}{c}0.33 \\
(0.03) \\
\end{array}$ & 0.48 & $76 \%$ \\
\hline \multirow{3}{*}{$\begin{array}{l}\text { Total Dollar Amount Spent } \\
\text { on DTCA }\end{array}$} & Intercept (Brand A) & $\varphi_{0 p 1}$ & $\begin{array}{r}-11.36 \\
(0.09)\end{array}$ & 2.29 & $100 \%$ \\
\hline & Intercept (Brand B) & $\varphi_{0 p 2}$ & $\begin{array}{l}-9.59 \\
(0.11)\end{array}$ & 2.26 & $100 \%$ \\
\hline & Intercept (Brand C) & $\varphi_{0 p 3}$ & -9.24 & 2.24 & $100 \%$ \\
\hline
\end{tabular}




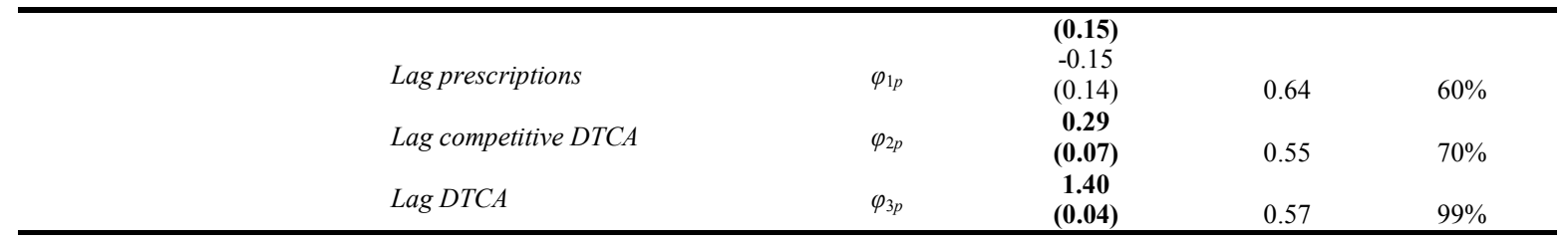

* Bold numbers in column 4 indicate that 0 lies outside of the $95 \%$ highest posterior density interval of the estimate for the population mean.

First, all the brands we analyzed, while still heavily advertised (Atherly and Rubin 2009), are mature brands. Previous research has shown that advertising elasticities decrease as markets mature (Kolsarici and Vakratsas 2010, Vakratsas and Ambler 1999).

Second, in our observation window, branded drug advertisements are more common than unbranded drug advertisements. Branded drug advertisements typically contain a laundry list of side effects, mandated by the FDA from the manufacturer, which may intimidate patients, blocking them from cognitively processing the ad, and may outweigh the benefits of treatment mentioned in the ad (Kolsarici and Vakratsas 2010, Wang 2008). An average of 18 seconds across all one-minute TV commercials in our sample were spent on mentioning possible risks, such as warnings against drug use for patients with liver disease, pregnant women, woman that might become pregnant, nursing women, patients taking other medication, etc., In addition, all commercials caution against serious side effects due to drug use, and indicate weakness and muscle pain as possible warning signals. Thus, the ads in this period may have effectively scared patients rather than attracted them to make brand-specific drug requests.

Third, local DTCA in the investigated time frame for the respective brands is only about $6 \%$ of the national DTCA expenditures for those brands, causing little variance in DTCA exposure across DMAs. It is conceivable that categories and time frames with higher levels of local DTCA may also show different DTCA effects. 
We find that drug requests have a positive effect on the number of prescriptions $\left(\beta_{1 p}=1.10\right.$, std. $\left.=0.06\right)$. The long-run impact of drug requests is accounted for through the inclusion of lagged prescriptions in the prescription equation. As the exact expressions for the cumulative or long-term effect of an additional request do not exist in closed form, we follow the approach suggested by Manchanda et al. (2005) and provide a local approximation for this derivative for each physician. This is given by $\beta_{1 p \text { longrun }}=\frac{\beta_{1 p}}{1-\beta_{8 p}}$, which for most physicians is positive. We report the distribution of the long-run request effect in graphical form in Figure 3.

Figure 3. Histogram: Long-Run Effect of Patients' Requests on Number of Prescriptions

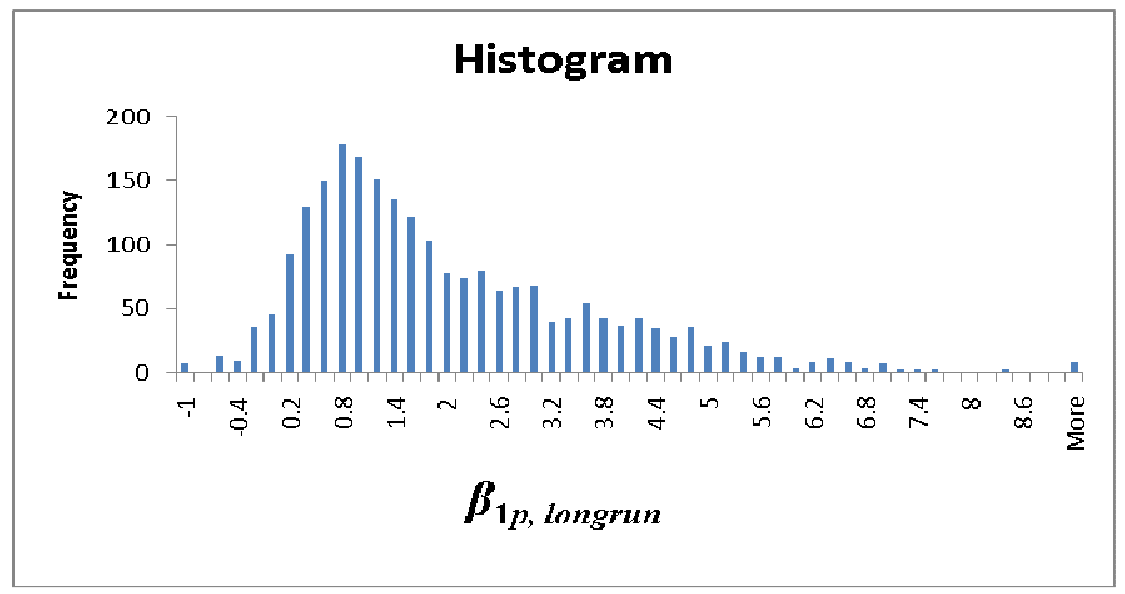

On average, the long-run effect of drug requests on the number of prescriptions is 1.69. That is, an additional drug request by brand name increases the long-run expected number of prescriptions for that same brand by almost two. Studies in medicine and social science have suggested several possible explanations for a positive influence of drug requests on the number of prescriptions. First, physicians may accommodate requests in order to increase patient satisfaction (Kravitz et al. 2003, Uhlmann et al. 1988) and to signal that they care about the patient (Prosser et al. 2003, Schwartz et al. 1989). Second, physicians might fear that refusing a request compromises the trusting relationship with their patients (Berger et al. 2001) and may 
even lead to patient defection (Stevenson et al. 2000). A third possible reason for request accommodation may be that physicians lack the time to change patients' minds and try to avoid conflict (Prosser et al. 2003, Schwartz et al. 1989, Stevenson et al. 2000). Finally, studies have suggested that physicians accommodate requests in the hope that prescribing a requested drug makes the patient more compliant (Uhlmann et al. 1988, Webb and Lloyd 1994).

\subsubsection{Other Effects}

The estimates show a higher base prescription level for Brand $\mathrm{A}\left(\beta_{0 p 1}=-1.20\right)$ than for Brand $\mathrm{C}$ $\left(\beta_{0 p 3}=-2.01\right)$, and Brand $\mathrm{B}\left(\beta_{0 p 2}=-2.78\right)$, befitting their observed market shares.

As expected, we found a positive effect of detailing on prescriptions $\left(\beta_{2 p}=0.60 ;\right.$ std. $=0.02$ ). The average long-run effect of detailing, calculated in a similar fashion to the long-run effect of drug requests, is 0.85 . This effect size is similar to what has been found in prior studies (e.g. Kremer et al. 2008). We calculated the ROI for a detailing visit, based on data from IMS Health and from Consumer Reports ${ }^{8}$ on the periodic revenue per prescription for the brand. We assess a detailing visit cost to be $\$ 150$, based on data from Quintiles, the largest provider of pharmaceutical sales services. Given that each detailing visit typically covers three brands, we take $\$ 50$ as the cost of a detailing visit per brand. We found that the ROI of a detailing visit is 1.51 , which means that a $\$ 1$ detailing increase leads to a $\$ 1.51$ increase in prescription revenue.

Competitive prescriptions have a positive effect on the number of prescriptions $\left(\beta_{5 p}=0.78\right.$, $s t d .=0.02)$, likely due to category growth (Mizik and Jacobson 2004). Competitive requests, on the other hand, do not have a significant effect on the number of prescriptions $\left(\beta_{6 p}=0.01, s t d\right.$. $=$ 0.03). Likewise, lagged mean prescriptions in the DMA do not have an effect on the number of

\footnotetext{
${ }^{8}$ IMS Midas price system and Consumer Reports Best Buy Drugs: The Statin Drugs (Jan, 2006).
} 
prescriptions $\left(\beta_{7 p}=0.02, s t d .=0.02\right)$. Lagged prescriptions at the physician level have a positive effect on the number of prescriptions $\left(\beta_{8 p}=0.27, s t d .=0.01\right)$, which may be due to within-practice word-of-mouth or prescription inertia (Coscelli 2000, Janakiraman et al. 2008).

The estimates of the drug request equation show a higher base request level for Brand $\mathrm{A}$ $\left(\alpha_{0 p 1}=-5.82\right)$ than for Brand C $\left(\alpha_{0 p 3}=-6.66\right)$, than for Brand B $\left(\alpha_{0 p 2}=-7.87\right)$. Lagged prescriptions have a negative effect on the number of requests $\left(\alpha_{3 p}=-0.33\right.$, std. $\left.=0.04\right)$. While this effect may comprise word-of-mouth effects among patients, which are typically positive, it may also comprise visit persistence by the same patient. As a prescription typically covers a treatment period of three months, few patients who received a prescription in a given month would return the following month to make a request, causing this effect to turn negative.

The estimates of the detailing equation show that Brands $\mathrm{A}$ and $\mathrm{C}$ have the highest numbers of detailing visits $\left(\gamma_{0 p 1}=-2.15 ; \gamma_{0 p 3}=-2.15\right)$, followed by Brand $\mathrm{B}\left(\gamma_{0 p 2}=-3.59\right)$, consistent with observed detailing shares. Physicians who prescribe more $\left(\gamma_{1 p}=0.57\right.$, std. $\left.=0.03\right)$ or receive more detailing visits from competitors $\left(\gamma_{2 p}=0.36, s t d .=0.02\right)$ receive more sales calls. We find significant state-dependence in detailing $\left(\gamma_{3 p}=0.33\right.$, std. $\left.=0.03\right)$.

The estimates of the DTCA equation show a lower base DTCA spending level for Brand $\mathrm{A}\left(\varphi_{0 p 1}=-11.36\right)$ than for Brand B $\left(\varphi_{0 p 2}=-9.59\right)$, than for Brand C $\left(\varphi_{0 p 3}=-9.24\right)$. Lagged prescriptions have no significant effect on DTCA spending $\left(\varphi_{1 p}=-0.15\right.$, std. $\left.=0.14\right)$, which fits the volatility in month-to-month spending we observed in the raw data (see Figure 1). Lagged competitive spending has a positive effect on DTCA spending $\left(\varphi_{2 p}=0.29\right.$, std $\left.=0.07\right)$, showing that firms tend to run campaigns after competitors have done so. Finally, DTCA shows substantial inertia $\left(\varphi_{3 p}=1.40\right.$, std. $\left.=0.04\right)$.

\subsection{Second-Layer Estimates}


Table 3 presents the second-layer estimates of our system of four equations. We present the mean and the standard deviation of the second-layer estimates for each of the eight first-layer parameters we decompose in our model (i.e., $\beta_{0 j p}, \beta_{1 p}, \beta_{2 \mathrm{p}}, \beta_{3 \mathrm{p}}, \alpha_{0 j p}, \alpha_{1 p}, \gamma_{0 j p}$ and $\left.\varphi_{0 \mathrm{j} p}\right)^{9}$.

\subsubsection{From Requests to Prescriptions: Specialty and Spatial Variation}

In Table $3 \mathrm{~A}$, our main interest lies in parameters $\omega_{11}-\omega_{18}$, in columns $5-7$. We find that drug requests to specialists translate into fewer prescriptions than do drug requests to primary care physicians $\left(\omega_{11}=-0.78\right.$, std. $\left.=0.15\right)$. Specialists have greater intellectual mastery over their specialties than do primary care physicians (Kravitz et al. 2003), which may enable them to convince patients more easily that the requested drug is not their drug of choice.

As for spatial variation, we find that drug requests in DMAs with higher proportions of minorities - notably Blacks $\left(\omega_{12}=-0.99\right.$, std. $\left.=0.59\right)$ and Hispanics $\left(\omega_{13}=-1.72\right.$, std. $\left.=0.52\right)-$ translate into fewer prescriptions, as compared to DMAs with lower proportions of minorities. A likely reason is that the medical interview is less participatory for minorities than it is for Whites. Minority patients have been found to be less assertive in physician-patient interactions and more respectful of the physician-patient hierarchy (Street et al. 2005, Tamayo-Sarver et al. 2003, Young and Klingle 1996), and are thus probably less persistent in pursuing the prescription of their requested drugs. Minorities were also found to have a lower evaluation of physicians when it came to communication that involved patient input and empathy (Hooper et al. 1982).Blacks, were found to rate their visits with physicians as less participatory (Cooper-Patrick et al. 1999, Kaplan et al. 1995). We were also able to rule out the following alternative explanations.

\footnotetext{
${ }^{9}$ The second layer parameters are not estimated at the physician level as they capture the effect of physician characteristics that do not vary over time. Rather, these parameters are fixed across our population of physicians. Thus, the posterior credibility intervals represent the probability that zero lies outside the $95 \%$ highest posterior density interval for the sample draws from these parameters in our MCMC procedure.
} 
Table 3A. From Requests to Prescriptions: Specialty and Spatial Variation (2 ${ }^{\text {nd }}$ Layer)

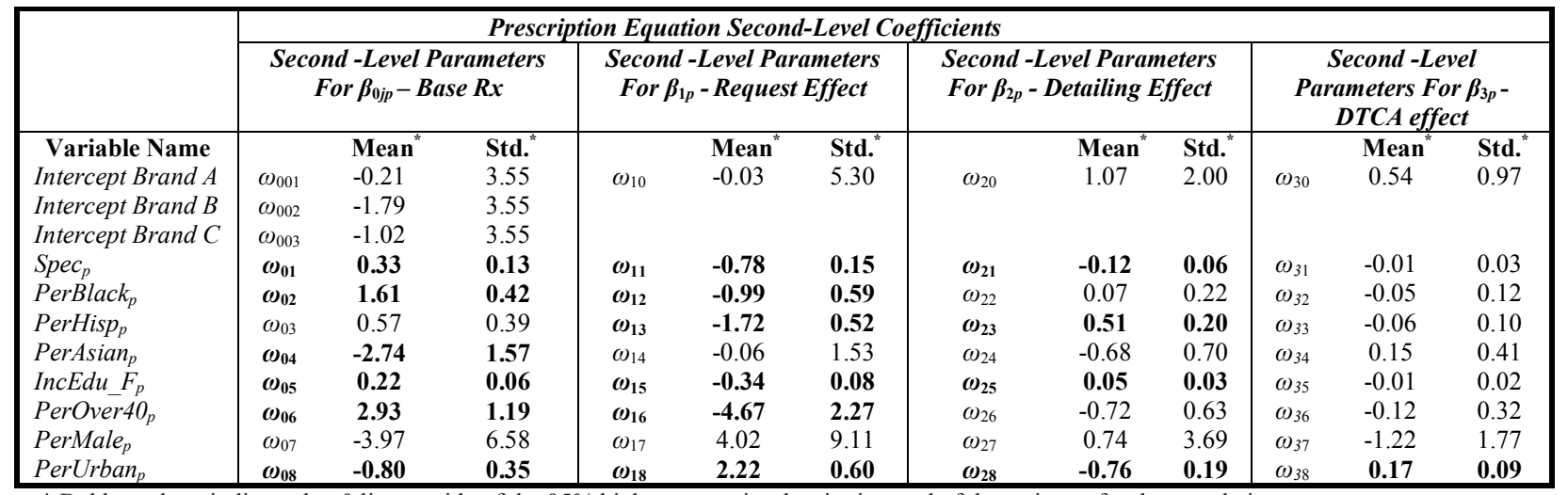

* Bold numbers indicate that 0 lies outside of the $95 \%$ highest posterior density interval of the estimate for the population mean.

Table 3B. From DTCA to Requests: Specialty and Spatial Variation (2nd Layer)

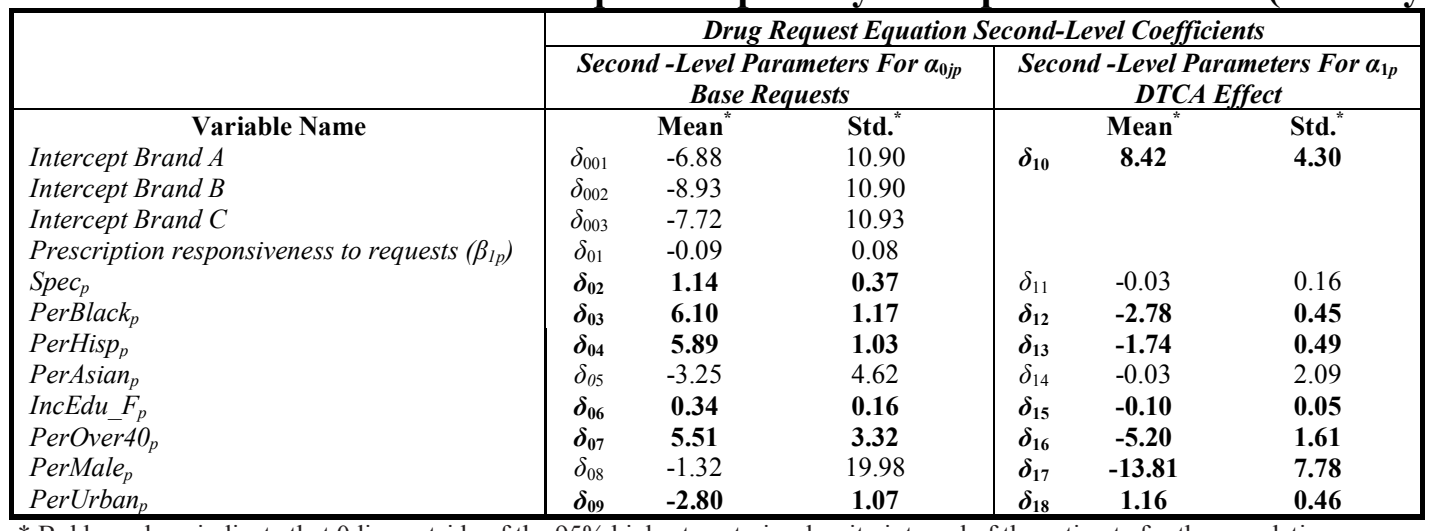

* Bold numbers indicate that 0 lies outside of the $95 \%$ highest posterior density interval of the estimate for the population mean.

Table 3C. Second-Layer Estimates of the Detailing Equation

\begin{tabular}{|c|c|c|c|}
\hline & \multicolumn{3}{|c|}{$\begin{array}{c}\text { Detailing Equation Second -Level Parameters } \\
\text { For } \gamma_{0 p j}-\text { Base Detailing }\end{array}$} \\
\hline Variable Name & & Mean & Std." $^{\circ}$ \\
\hline Intercept Brand $A$ & $\rho_{001}$ & -1.81 & 0.09 \\
\hline Intercept Brand B & $\rho_{002}$ & -3.25 & 0.13 \\
\hline Intercept Brand C & $\rho_{003}$ & -1.80 & 0.09 \\
\hline Prescription responsiveness to detailing $\left(\beta_{2 p}\right)$ & $\rho_{01}$ & -0.57 & 0.09 \\
\hline
\end{tabular}

* Bold numbers indicate that 0 lies outside of the $95 \%$ highest posterior density interval of the estimate for the population mean.

Table 3D. Second-Layer Estimates of the DTCA Equation

\begin{tabular}{|c|c|c|c|}
\hline & \multicolumn{3}{|c|}{$\begin{array}{c}\text { DTCA Equation Second-Level Parameters } \\
\text { For } \varphi_{0 \mathrm{pi}}-\text { Base DTCA }\end{array}$} \\
\hline Variable Name & & Mean $^{*}$ & Std. $^{*}$ \\
\hline Intercept Brand $A$ & $\mu_{001}$ & -27.61 & 1.32 \\
\hline Intercept Brand B & $\mu_{002}$ & -25.84 & 1.23 \\
\hline Intercept Brand C & $\mu_{003}$ & -25.49 & 1.22 \\
\hline Request responsiveness to DTCA $\left(\alpha_{1 p}\right)$ & $\mu_{01}$ & -0.008 & 0.04 \\
\hline Prescription responsiveness to requests $\left(\beta_{1 p}\right)$ & $\mu_{02}$ & -0.02 & 0.04 \\
\hline Prescription responsiveness to DTCA $\left(\beta_{3 p}\right)$ & $\mu_{03}$ & 0.03 & 0.11 \\
\hline Household $T V_{p}$ & $\mu_{04}$ & 1.20 & 0.08 \\
\hline
\end{tabular}

* Bold numbers indicate that 0 lies outside of the $95 \%$ highest posterior density interval of the estimate for the population mean. 
As we control for education, it is unlikely that the effect is caused by difficulties of minorities to express themselves with physicians (Helman 1994). Moreover, the coefficient for income and education shows that requests are accommodated less frequently in high-income, high-education DMAs, not more frequently $\left(\omega_{15}=-0.34\right.$, std. $\left.=0.08\right)$.

A second alternative explanation we ruled out is that minorities may have different cardiovascular conditions. Blacks have higher heart-disease-related mortality rates than Whites do, but Hispanics typically have lower mortality rates due to heart disease than Whites (Centers for Disease Control and Prevention, 2000, http://www.cdc.gov/). Thus the cardiovascular condition cannot explain the similar lower request effects on prescriptions for both areas with higher percentages of Blacks and areas with higher percentages of Hispanics.

A third alternative explanation we ruled out is that DMAs with higher proportions of Whites may contain more physicians than DMAs with higher proportions of minorities. A higher number of physicians may lead physicians to accommodate drug requests more easily, because of increased competition between physicians (Bell et al. 1999, Kravitz 2000). However, we found no significant correlation between the number of physicians per capita and the minority composition of a region, whether defined according to ZIP code or DMA. Also, when we control for the number of physicians in the DMA, the model's coefficients remain robust.

Beyond the minority composition of the DMA, we found that the age distribution of a DMA may also be a source of regional variation in request accommodation. Drug requests by brand name are less likely to translate into prescriptions in DMAs that have higher proportions of people over $40\left(\omega_{16}=-4.67\right.$, std. $\left.=2.27\right)$. Older patients may suffer more from drug interactions (Donohue and Berndt 2004) or side effects (e.g. myopathy is a common side effect of statins 
among the elderly (Daugird and Crowell 2003)). In addition, physicians are typically more communicatively dominant with patients over 40 (Street and Buller 1988).

Finally, we find that the gender distribution of a DMA does not explain spatial variation in request accommodation and that urban DMAs exhibit significantly higher request accommodation rates than do rural DMAs $\left(\omega_{18}=2.22\right.$, std. $\left.=0.60\right)$. Traditional norms and values persist for a longer time in rural areas than in urban areas. Thus, one may expect patients and physicians in rural areas to preserve the traditional physician-patient hierarchy more than is the case in urban areas, leading to lower influence of the patient on the physician (also see Deveugele et al. 2002).

Columns $9-10$ and columns $12-13$ of Table 3 A show the estimation results of the secondlevel parameters for responsiveness to detailing and to DTCA, respectively. Among these, the most interesting finding is that specialists are less responsive to detailing visits compared to primary care physicians $\left(\omega_{21}=-0.12\right.$, std. $\left.=0.06\right)$.

\subsubsection{From DTCA to Requests: Specialty and Spatial Variation}

In Table 3B, our main interest lies in the parameters $\delta_{10}-\delta_{18}$, in columns 5-7. We find that while specialists receive more drug requests $\left(\delta_{02}=1.14\right.$, std. $\left.=0.37\right)$, drug requests to specialists are not disproportionally triggered by DTCA compared to drug requests to primary care physicians $\left(\delta_{11}=-0.03\right.$, std. $\left.=0.16\right)$. Patients who see a specialist typically have more severe medical conditions than patients who see a primary care physician and may therefore be more involved and informed (Gould 1988), and thus more likely to make a request. Apparently, the increased involvement and information does not come from direct-to-consumer ads, but may come from alternate sources, which we were unable to cover in the present study, such as word-of-mouth, online searches, discussion with the primary care physician before referral, etc. 
As for regional variation, we find that the number of drug requests triggered by DTCA is lower in DMAs with higher proportions of Blacks and Hispanics than in DMAs with lower proportions of Blacks and Hispanics $\left(\delta_{12}=-2.78\right.$, std. $=0.45 ; \delta_{13}=-1.74$, std. $\left.=0.49\right)$, even though the former DMAs show a higher number of drug requests by brand name $\left(\delta_{03}=6.10\right.$, std. $=1.17$; $\delta_{04}=5.89$, std. $\left.=1.03\right)$. This finding fits earlier findings that among all ethnic groups, Hispanics show the lowest effect of drug advertising on patients' check-up visits (Cantor 2010, Hosken and Wendling 2009). A visual inspection of the ads for the three investigated brands over the analyzed time period reveals that the vast majority of models participating in these ads are White. This finding fits with prior research that has also shown that Blacks and Hispanics are highly underrepresented in drug advertisements; studies of magazine advertisements for heart disease medication did not find such ads in any magazines targeting the Black population, and a vast majority (over 90\%) of the models across all investigated ads were White (Mastin et al. 2007, Omonuwa 2001, Welch et al. 2004). Social identity theory would imply that Blacks and Hispanics may give less attention to such advertisements, leading to lower DTCA effectiveness in generating drug requests among Blacks and Hispanics. Barg and Greir (2008) suggest that marketing efforts that are based on a "mass appeal" may contribute to disparities in health preventive behaviors. Research in the domain of preventive care for breast cancer, argues that because marketing communications in this domain are concentrated around women who are White, straight, middle- to upper class, urban, educated and professional (Cartwright, 1998), they have low appeal and elicit low levels of identification among lower-income Black women.

Among the other socio-demographic variables, the income and education distribution, the age distribution, gender distribution and the level of urbanization of a DMA significantly moderate the effect of DTCA expenses on the number of requests. In DMAs with higher income 
and education levels, a higher percentage of people over 40 or a higher percentage of males, and in more rural DMAs, DTCA expenditures are less effective in triggering drug requests than in DMAs with lower income and education levels, a lower percentage of people over 40 , and a lower percentage of males, and in urban DMAs $\left(\delta_{15}=-0.10\right.$, std. $=0.05 ; \delta_{16}=-5.20$, std. $=1.61$; $\delta_{17}=-13.81$, std. $=7.78 ; \delta_{18}=1.16$, std. $\left.=0.46\right)$. Moreover, the relatively large number of more urban DMAs across the U.S. (see Figures 4 and 5) may also explain the high representation of negative values in the distribution of $\alpha_{1 p}$ (the effect of DTCA on number of requests).

We further compared physicians for whom we find a significant positive effect of DTCA on requests with physicians for whom we find a significant negative effect of DTCA on requests ${ }^{10}$. Consistent with our findings above, we find that physicians associated with a positive effect of DTCA on requests practice in DMAs that are more urban (DMA urbanization levels of $80.9 \%$ vs. $69 \%$ for physicians associated with positive and negative effects, respectively), have a lower percentage of Blacks and Hispanics (mean percent Blacks 8.6\% vs. 25.6\%; mean percent Hispanics $11.3 \%$ vs. $12.0 \%$, for positive and negative effects, respectively), and have a lower percentage of population over the age of 40 (mean percent $40.4 \%$ vs. $43.7 \%$, for positive and negative effects, respectively) than the DMAs of physicians associated with a negative effect.

In addition, we find that the responsiveness of physicians to requests is not a significant determinant of the number of requests $\left(\delta_{01}=-0.09 ; s t d .=0.08\right)$.

\subsubsection{Factors Affecting Detailing and DTCA}

Tables 3C and 3D present the second-level effects for the intercepts in the detailing and DTCA equations, respectively. First, we find that the responsiveness of the physician to detailing visits

\footnotetext{
${ }^{10}$ Significance is defined based on the $90 \%$ posterior interval for the draws of this parameter for the physician.
} 
has a negative effect on the base level of detailing for the physician $\left(\rho_{01}=-0.57\right.$, std. $\left.=0.09\right)$. This finding is consistent with a similar finding in the work of Manchanda et al. (2005).

For DTCA spending, we find that while DTCA expenses are higher in DMAs where a greater number of households own a television set $\left(\mu_{04}=1.20\right.$, std.$\left.=0.08\right)$, they are not dependent upon the responsiveness of prescriptions to DTCA $\left(\mu_{03}=0.03\right.$, std. $\left.=0.11\right)$, prescriptions to requests $\left(\mu_{02}=-0.02\right.$, std. $\left.=0.04\right)$ or requests to DTCA $\left(\mu_{01}=-0.008\right.$, std. $\left.=0.04\right)$.

\subsection{Robustness}

To assess the robustness of our results, we checked whether the insignificant effect of DTCA on physician prescriptions mask an interaction effect between DTCA and the number of drug requests a physician gets. We included this interaction term and found it not significant. ${ }^{11}$

Second, we re-estimated our model also including the fourth and the fifth most prescribed brands in the category as well (covering roughly $85 \%$ of the category). These brands are detailed much less than the three most prescribed brands and were not advertised during the investigated time frame. Our main estimation results remain the same.

Third, we also estimated our model with spatial variation at the ZIP code level, rather than at the DMA level and find our main findings to hold. The only exception is the level of urbanization, for which the effects in the second layer of the model are the reverse of what we report above. Physician offices are often located in urban areas, which may cause the second layer effects of urbanization at the ZIP code level to deviate from those at the level of the DMA.

\footnotetext{
${ }^{11}$ All results presented in this section are available from the authors upon request.
} 
Fourth, our prescription variable includes total number of prescriptions, as we cannot distinguish between requests for new drug prescriptions or refills (i.e., a request to continue treatment). We have estimated our model excluding refills. We find that our main findings hold.

Fifth, while we added 1 to the variables in our log-log transformation to avoid zeros, as is common (e.g. Manchanda et al. 2005), we also estimated the model with the addition of 2 instead of 1 . The main results are similar to the results of our model reported above.

Sixth, because of lack of direct, observational data at the patient level, the second layer of our model uses region-level socio-demographics as moderators, rather than patient-level moderators. Therefore, we also ran a dyadic, patient-physician-level simulation in order to demonstrate that the NBD model we estimate can recover patient-level effects. We find that the dyadic effects are reflected in the aggregate estimation results, as represented by our NBD model. We also find that if the simulation data include a significant effect of DTCA on requests at the individual level, our model at the aggregate level can indeed recover this effect. Although our study takes place in a different setting, the approach we undertake here can be viewed as bearing a strong resemblance to the approach outlined by Musalem et al. (2008), who recovered consumer-level coupon utilization using aggregate market-share and coupon-redemption volume alone. Moreover, since the patient-physician level simulation exercise does not allow us to evaluate the estimation procedure's ability to recover the true parameters underlying the observed behavior, we also performed a simulation exercise in which we estimate equations (1)(12) using data simulated with known parameters. We then evaluated whether the estimation recovers those parameters. The comparison of the estimated values and simulated values in this second simulation illustrates that our estimation procedure recovers the underlying parameters for the data. Both first and second layer parameters were found to be very similar to the values 
used to generate the data. Overall the second simulation provides us with additional validation for our estimation procedure's ability to recover the true parameters underlying the observed behavior in our data (see Web Appendix B for details on both simulation exercises).

Seventh, there is a moderate negative correlation of -0.46 between the percentage of Blacks in a DMA (PerBlack) and the percentage of males (PerMale) in the DMA. This value might be a result of the very low standard deviation of the PerMale variable in our sample (mean $=0.49$, std. $=0.01)$. While we cannot explain this moderate negative correlation, we re-estimated our model excluding PerMale in all second level equations in order to alleviate a multicolinearity concern that the -0.46 correlation lowers the PerBlack coefficient. The estimation results are very similar to those of the model that includes PerMale. More specifically the significance, as well as the sign, of the estimated PerBlack effect is similar in both estimation runs. All other estimates of the second level parameters are also very similar in sign and significance level to those of the original estimation results. We therefore conclude that the -0.46 correlation between percentage of PerBlack and PerMale does not affect our estimation result.

Eight, to further empirically validate our second-layer DMA-level findings at the dyadic level, we conducted a patient survey. We gathered data from 6,635 U.S. patients ${ }^{12}$. The first part of the survey, which was answered by all participants, contained questions regarding the effect of DTCA on request behavior among patients. The second part of the survey contained specific questions regarding patient requests and the patient-physician relationship. Respondents who indicated that they had never requested a drug by brand name either from their primary care

\footnotetext{
${ }^{12}$ The survey was conducted online between October $22^{\text {nd }}$ and November $10^{\text {th }}, 2009$ by a market research firm using a panel of U.S. participants. The data were then weighted in order to represent the U.S. demographic decomposition.
} 
physician or from a specialist did not participate in the second part of the survey. In our sample of patients, $67 \%$ reported having requested drugs by brand name.

While using a completely different methodology (self-reports) than the NBD model on behavioral data, the survey lends support to our main second-layer findings. Table 4 reports the estimation results of an ordinal regression with the frequency of patient request accommodation as a dependent variable ${ }^{13}$. As in our NBD model estimation results, patients report higher accommodation frequencies of primary care physicians than of specialists $(e s t .=0.52 ; p<0.01)$. Again, as in our NBD model estimation results, we find that Blacks $(e s t .=-0.27 ; p<0.01)$ and Hispanics (est. $=0.32 ; p<0.01)$ report significantly lower accommodation frequencies than do Whites. As in our NBD model estimation results, the age of the patient has a negative effect on request accommodation (est. $=-0.02 ; p \leq 0.01)$. In contrast to our NBD model, the effect of a factor composed of income and education on request accommodation is positive (est. $=0.15 ; p<0.01)$ rather than negative. We do not find a significant effect of the remaining demographics on request accommodation frequency.

We also examined whether Blacks and Hispanics were less influenced by DTCA as compared to Whites, as reported on the basis of the NBD model in Table 3B. Respondents were asked whether they had ever talked to their physicians based on an advertisement for a prescription drug displayed on television or in a magazine. Of the total survey population, $30.2 \%$ answered 'yes'. Respondents who answered 'yes' were then asked about the nature of the discussion. Consistent with our model estimation results, the percentage of Blacks and Hispanics requesting a prescription for an advertised drug (23.6\% for Blacks and $26.7 \%$ for Hispanics) was

\footnotetext{
${ }^{13}$ The questions comprising the dependent variable are: "How often did your primary care physician accommodate your requests for prescription drugs?" and "How often did your specialist accommodate your requests for prescription drugs?"
} 
lower than the percentage of Whites requesting a prescription for an advertised drug $(31.9 \%$ for Whites). For Asians, the corresponding percentage was $28.3 \%$. These percentages are relatively large, as compared to our NBD results. This may suggest that the effect of DTCA on drug requests from our 2002-2003 statin sample is small, compared to the effects one may find in other drug categories or more recent time window.

Table 4: Estimation Results: Ordinal Regression for Request Accommodation

\begin{tabular}{|c|c|c|c|}
\hline & & Estimate & Std. Error \\
\hline Specialty & $\begin{array}{l}\text { Primary care physician } \\
\text { Specialist }\end{array}$ & $\begin{array}{c}0.52^{* *} \\
0^{\mathrm{a}}\end{array}$ & $\begin{array}{c}0.04 \\
.\end{array}$ \\
\hline Minorities & $\begin{array}{l}\text { Black } \\
\text { Hispanic } \\
\text { Asian } \\
\text { Other } \\
\text { White }\end{array}$ & $\begin{array}{c}-0.27 * * \\
-0.32 * * \\
-0.15 \\
0.07 \\
0^{\mathrm{a}}\end{array}$ & $\begin{array}{l}0.07 \\
0.09 \\
0.12 \\
0.13\end{array}$ \\
\hline $\begin{array}{l}\text { Patient Demographic } \\
\text { Characteristics }\end{array}$ & $\begin{array}{l}\text { Urbanization } \\
\text { Income Education Factor } \\
\text { Age } \\
\text { Male } \\
\text { Female }\end{array}$ & $\begin{array}{c}-0.006 \\
0.15^{* *} \\
-0.02 * \\
0.02 \\
0^{\mathrm{a}}\end{array}$ & $\begin{array}{l}0.02 \\
0.02 \\
0.01 \\
0.04 \\
.\end{array}$ \\
\hline $\begin{array}{l}\text { Patient-Physician } \\
\text { Relation }\end{array}$ & Length of Relationship ${ }^{b}$ & -0.04 & 0.03 \\
\hline
\end{tabular}

\section{Implications for Managers and Policy Makers}

In this paper, we introduce a comprehensive model that uncovers the DTCA - requests prescriptions chain. It also uncovers variation along the entire chain, dependent on DMA (i.e. the socio-demographic make-up of the DMA) and physician specialty, leading to insights that are of interest to both managers and policy makers.

While many managers in pharmaceutical firms express high expectations as to the effectiveness of DTCA in increasing patient requests for their own brands, we show here that 
DTCA may not always deliver upon these high expectations. In our study of the statin category between 2002 and 2003, we find that the average effect of DTCA on patient requests is very small, i.e. it is negligible for $93 \%$ of physician practices, while it is negative for $6 \%$ of the practices and positive for only $1 \%$ of the practices. Thus, in our sample (i.e. category and time period), DTCA only has the expected positive effect on requests in $1 \%$ of practices. These practices are typically located in urban DMAs with a high proportion of young Whites.

We can also graphically depict the spatial pattern we observed across DMAs in the responsiveness of drug requests to DTCA spending (see Figure 4). Such a geographical map can provide marketing managers with a better understanding of where DTCA spending leads to desired increases in drug requests by brand name. By extension, one can configure a similar map for physician prescription responsiveness to patient drug requests (see Figure 5). The combination of both would allow marketing managers to infer in which markets they could generate greater ROI from DTCA (as measured by increased prescriptions through increased requests). Furthermore, pharmaceutical firms could proactively reach out to areas with accommodating physicians. In the category and time frame of our study, we documented that firms only spend $6 \%$ of their national DTCA budget on local DTCA. The spatial patterns we find may require firms to shift more of their spending from national media to local media in highly responsive areas. Conjecturing beyond the boundaries of our study, manufacturers may also consider targeting different patient groups, along their socio-demographic characteristics, using social media (such as Twitter, Facebook, or specialized platforms such as PatientsLikeMe), rather than mass advertising. Such highly targeted media strategies may allow higher sensitivity to minorities, who may display different networking behavior and show different sensitivity to different forms of communication, as compared to majority populations. 


\section{Figure 4. Spatial Patterns in Drug Request Responsiveness to DTCA}

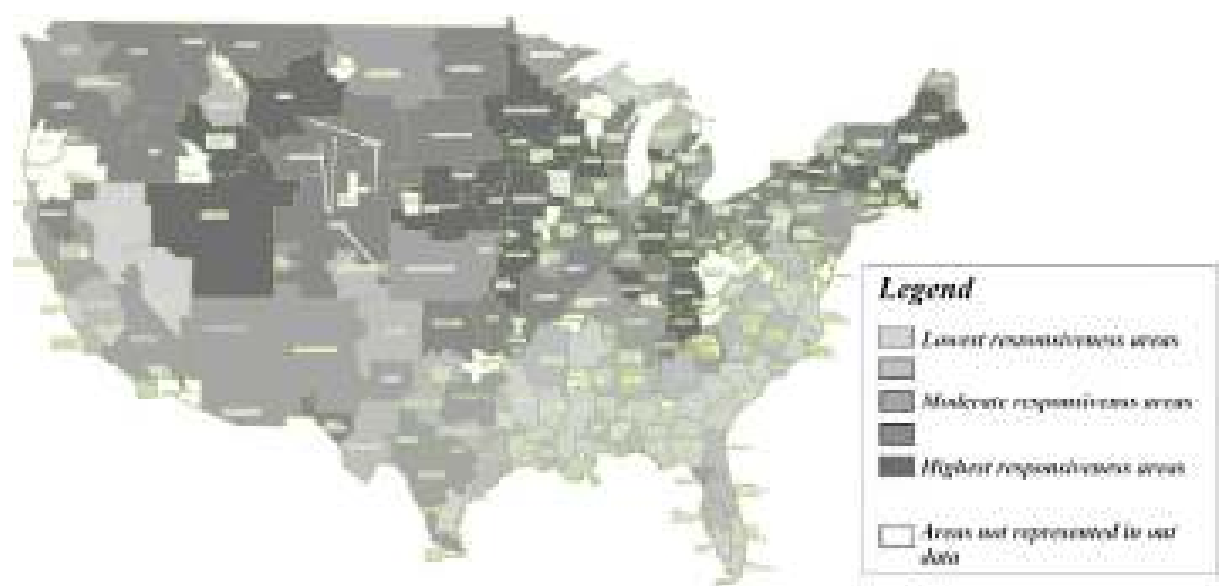

Figure 5. Spatial Patterns in Physicians' Responsiveness to Patient Drug Requests

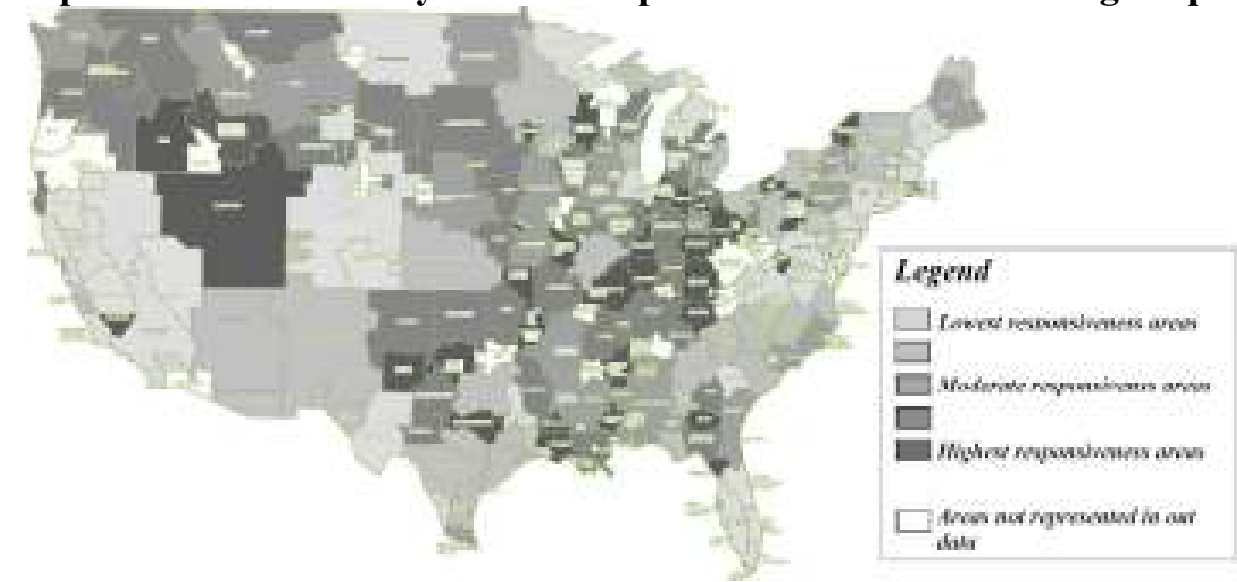

Overall, the effect of drug requests on prescriptions is large and positive, which may trigger public policy concerns. On the one hand, patient requests may potentially threaten the gatekeeping function of the physician if the physician prescribes drugs he would otherwise (i.e. without request) not prescribe. On the other hand, participation of the patient may lead to more shared decision-making between patient and physician. In this case, however, policy makers may want to monitor whether the right to participate in medical decisions is equally distributed across socio-demographic groups. Based on actual request and prescription data and self-reported survey data, we inventory large differences in accommodation behavior across DMAs, along socio-demographic characteristics such as DMA racial composition. 


\section{Future Research}

First, given the type of data we have, we cannot ascertain whether the drug requested by a given patient is the optimal treatment for the patient. Hence, future research that can offer such normative claims would be highly relevant to public policy makers.

Second, the insurance coverage of the patient may affect physicians' propensity to accommodate drug requests. Since our analysis involves insured patients $(97 \%$ of our data portrays prescription behavior for insured patients), the mere question of insurance coverage is not likely to affect our results. Moreover, the effect of insurance type may relate to the age variable and the factor score $I n c E d u \_F$. Still, it would be interesting if future research could reveal differential requesting and request accommodation behavior across insurance types.

Third, we studied only one category, namely, statins. While the statin category is the largest drug category in our data window, and while our survey results are non-malady-specific, our study would benefit from replications in other categories.

Fourth, we used monthly data for prescriptions, requests, detailing, and DTCA. If researchers can obtain data with a higher periodicity (e.g. daily), it would allow for a richer model of the dynamics in these behaviors. In addition, as the insights we obtain are obviously bounded by the variance in our data, we cannot gauge the consequences of a policy shift in DTCA, e.g., the number of prescriptions a firm would lose were it to drop DTCA to zero.

Fifth, we do not have patient-level data, which limits our insights regarding the extent to which our findings are driven by a small number of patients repeatedly requesting drugs by brand name, or a large number of patients requesting drugs by brand name infrequently. The survey we conducted indicates that a third of the population of patients above the age of 18 (33\%) report having requested prescription drugs by brand name from a primary care physician 
multiple times (i.e., they request drugs by brand name "sometimes", "most of the time" or "all the time"). An additional $35.4 \%$ of the patients say that they have requested branded drugs, but do so only rarely, and $32.2 \%$ respond that they have never requested a drug by brand name. This suggests that drug requests by brand name are common and that our results may be representative of a large population of patients requesting drugs by brand name.

Sixth, we do not observe drug sampling. While one may conceive of sampling as a determinant of future request behavior, such a conception would not fit prior findings in the same category. Venkataraman and Stremersch (2007), in the same therapeutic category, have concluded that samples are given as a financial subsidy to prescriptions rather than being used as a trial after which patients request a prescription for the drug. Moreover, sampling may be heavily correlated with detailing, for which we control. Still, sampling is under-researched, and connecting it to requesting and request accommodation behavior may yield interesting insights.

Seventh, our model does not control for patients possibly selecting physicians based on the degree to which they accommodate requests. Our survey results show that this may not be a cause for great concern, as patients do not switch physicians often (the average relationship duration is 8 years); indeed, only a small minority $(<10 \%)$ is likely to switch physicians when a drug request is denied. Also, from our NBD model, we find that physicians who accommodate requests more frequently do not necessarily receive more requests.

Eighth, as we cannot distinguish between requests for new drug treatment versus refills, we model total drug requests and total prescriptions. If future research could obtain data that distinguish between requests for new drug treatment, competing drug treatment (i.e., switch requests) or refills, one could assess the possibly differential effects of such requests. Several papers in the medical literature specifically discuss situations in which patients request to switch 
from a previously prescribed drug or to continue using their prescribed drug (e.g., Prosser et al. 2003, Uhlmann et al. 1988). Thus, drug requests to continue treatment may be as important to study as drug requests to start a new drug treatment. In addition, our outcome variable is number of prescriptions rather than number of doctor visits or other outcomes. We refer readers to Liu and Gupta (2011) for a study on the effect of DTCA on doctor visits and visit outcomes.

Ninth, adding fixed effects for the DMA may further capture DMA-level variation beyond the lagged mean number of prescriptions written in the DMA (which is included in the model). However, this would entail adding 193 regional dummies to each of our 4 equations, which is cumbersome to estimate given the complexity of our model specification. In order to evaluate whether DMA specific effects explain a large share of the base prescriptions level, over and above the demographic characteristics of these DMAs, we have regressed these dummies on the errors from the second level equation for base level prescriptions (see Equation 3). We find that $90 \%$ of the DMA dummies are insignificant in explaining these errors. We therefore conclude that the risk of having a systematic unobserved DMA effect that may bias our estimation results is low. For similar reasons, we allow for heterogeneity across physicians in all first-level parameters, yet model a second layer only for the covariates that are of focal interest to this study.

In general, there exist many opportunities for future research on the interaction between patients and physicians. Requesting a drug by brand name is but one consumerist action that patients take, besides making specialty requests, and requests for diagnostics, all of which may affect the treatment decisions of the physician and the treatment compliance of the patient. Such consumerist actions, their effects for drug companies and the concerns they generate among public policy makers should be of great interest to marketing scholars. 


\section{References}

AdAge. 2011. U.S. ad spending grew 6.5\% in 2010 as auto surged and pharma hit a low. March 17 th, http://adage.com/article/mediaworks/u-s-ad-spending-grew-6-5-2010-auto-rose-pharma-fell/149436/.

Aikin, K. J., J. L. Swasy, A. C. Braman. 2004. Patient and Physician Attitudes and Behaviors Associated with DTC Promotion of Prescription Drugs - Summary of FDA Survey Research Results. U.S. Department of Health and Human Services, Food and Drug Administration, Center for Drug Evaluation and Research, Washington, DC.

Amaldoss, W., C. He. 2009. Direct-to-consumer advertising of prescription drugs: A strategic analysis. Marketing Science 28(3) $472-487$.

Armitage, K., L. Schneidermann, R. Bass. 1979. Response of physicians to medical complaints in men and women. Journal of the American Medical Association 241(20) 2186-2187.

Atherly, A., P. H. Rubin. 2009. The cost-effectiveness of direct-to-consumer advertising for prescription drugs. Medical Care Research and Review 66(6) 639-657.

Ayanian, J., A. Epstein. 1991. Differences in the use of procedures between women and men hospitalized for coronary artery disease. The New England Journal of Medicine 325(4) 221-225.

Bajari, P. 2003. A comment on Allenby, Chen and Yang. Quantitative Marketing and Economics 1(2) 277-283.

Barg, F. K., S. A. Greir. 2008. Enhancing breast cancer communications: A cultural models approach. International Journal of Research in Marketing 25(4) 335-342.

Bell, R. A., R. L. Kravitz, M. S. Wilkes. 1999. Direct-to-consumer prescription drug advertising and the public. Journal of General Internal Medicine 14(11) 651-657.

Bell, R. A., M. S. Wilkes, R. L. Kravitz. 1999. Advertisement-induced prescription drug requests: patients' anticipated reactions to a physician who refuses. The Journal of Family Practice $\mathbf{4 8} 446-452$.

Berger, J. T., P. Kark, F. Rosner, S. Packer, A. J. Bennett. 2001. Direct to consumer drug marketing: Public service or disservice? The Mount Sinai Journal of Medicine 68(3) 197-202.

Berry, S. T. 1994, Estimating discrete-choice models of product differentiation. Rand Journal of Economics 71 $242-262$.

Berry, S. T., J. Levinsohn, A. Pakes. 1995. Automobile prices in market equilibrium. Econometrica 63(4) 841-90.

Berry, S. T. 2003. Comment on "Bayesian Analysis of Simultaneous Demand and Supply" by Sha Yang, Yuxin Chen, Greg M. Allenby. Quantitative Marketing and Economics 1(3) 285-291.

Brekke, K. R., M. Kuhn. 2006. Direct to consumer advertising in pharmaceutical markets. Journal of Health Economics 25(1) 102130 .

Brooks, S. P., A. Gelman. 1998. General methods for monitoring convergence of iterative simulations. Journal of Computational and Graphical Statistics 7 434-455.

Bowser, R. 2001. Racial profiling in health care: An institutional analysis of medical treatment. Michigan Journal of Race and Law $779-133$.

Broyles, R. W., W. J. McAuley, D. Baird-Holmes. 1999. The medically vulnerable: Their health risks, health status, and use of physician care. Journal of Health Care for the Poor and Underserved 10(2) 186-200.

Calabro, S. 2003. In DTC-free Europe, just as many patients ask for brand drugs. Medical Marketing and Media 38(11) 3.

Calfee, J. E., C. Winston, R. Stempski. 2002. Direct-to-consumer advertising and the demand for cholesterol-reducing drugs. Journal of Law and Economics 45 673-690.

Cantor, J. 2010. Does direct to consumer advertising of antidepressants affect visits to physicians? Working paper.

Cartwright, A. 1998. Community and the public body in breast cancer media activism. Cultural Studies 12(2) 1171-1138.

Chintagunta, P., J. P. Dube, K.-Y. Goh. 2005. Beyond the endogeneity bias: The effect of unmeasured brand characteristics on household-level brand choice models. Management Science 51(5) 832-849.

Cohen, M. G., G. C. Fonarow, E. D. Peterson, M. Moscucci, D. Dai, A. F. Hernandez, R. O. Bonow, S. C. Smith, Jr. 2010. Racial and ethnic differences in the treatment of acute myocardial infarction: Findings from the get with the guidelines coronary artery disease program. Circulation $1212294-2301$. 
Cooper-Patrick, L., J. J. Gallo, J. J. Gonzales, H. T. Vu, N. R. Powe, C. Nelson, D. E. Ford. 1999. Race, gender, and partnership in the patient-physician relationship. Journal of the American Medical Association 282(6) 583-589.

Coscelli, A. 2000. The importance of doctors' and patients' preferences in the prescription decision. Journal of Industrial Economics 48(3) 349-369.

Daugird A. J., K. Crowell. 2003. Do statins cause myopathy? The Journal of Family Practice 52(12) 973-977.

Ding, M., J. Eliashberg. 2008. A dynamic competitive forecasting model incorporating dyadic decision-making. Management Science 54(4) 820-834.

Deveugele, M., A. Derese, A. van den Brink, J. Bensing, J. De Maeseneer. 2002. Consultation length in general practice: cross sectional study in six European countries. British Medical Journal 325 472-477.

Donohue, J. M., E. R. Berndt. 2004. Effects of direct-to-consumer advertising on medication choice: The case of antidepressants. Journal of Public Policy and Marketing 23(2) 115-127.

Draganska, M. D. Jain 2002. Structural models of competitive market behavior: An estimation approach using disaggregate data. working paper, Stanford University and North- western University

Dubé J. P., P. K. Chintagunta. 2003. Comment on Bayesian analysis of simultaneous demand and supply. Quantitative Marketing and Economics 1(3) 293-298.

Fischer, M., S. Albers. 2010. Patient - or physician - oriented marketing: What drives primary demand for prescription drugs? Journal of Marketing Research 47 103-121.

Gould, S. J. 1988. Consumer attitudes toward health and health care: A differential perspective. The Journal of Consumer Affairs 22(1) 96-118.

Hannan, E., H. Kilburn, J. O'Donnell, G. Lukacik, E. Shields. 1991. Interracial access to selected cardiac procedures for patients hospitalized with coronary artery disease in New York State. Medical Care 29 430-441.

Hannan, E., M. van Ryn, J. Burke, D. Stone, D. Kumar, D. Arani, W. Pierce, S. Rafii, T. A. Sanborn, S. Sharma, J. Slater, B. A. DeBuono. 1999. Access to coronary artery bypass surgery by race/ethnicity and gender among patients who are appropriate for surgery. Medical Care 37(1) 68-77.

Helman, C. G. 1994. Culture, Health and Illness, 3rd ed. Butterworth-Heinemann Ltd., Oxford, UK.

Henderson, B. 2002. IMS Study: U.S. physicians responsive to patient requests for brand-name drugs. IMS Intelligence.

Hildebrand, V., P. Van Kerm. 2009. Income inequality and self-rated health status: Evidence from the European community household panel. Demography 46(4) 805-825.

Hollon, M. F. 1999. Direct-to-consumer marketing of prescription drugs: Creating consumer demand," Journal of the American Medical Association, 281(4) 382-384.

Hooper, E. M., L. M. Comstock, J. M. Goodwin, J. S. Goodwin. 1982. Patient characteristics that influence physician behavior. Medical Care 20(6) 630-638.

Hosken, D., B. Wendling. 2009. Informing the uninformed: How drug advertising affects check-up visits. Working paper.

Iizuka, T., G. Z. Jin. 2005. The effect of prescription drug advertising on doctor visits. Journal of Economics and Management Strategy 14(3) 701-727.

Janakiraman, R., S. Dutta, C. Sismeiro, P. Stern. 2008. Physicians' persistence and its implications for their response to promotion of prescription drugs. Management Science 54(6) 1080-1093.

Kaplan, S. H., B. Gandek, S. Greenfield, W. Rogers, J. E. Ware. 1995. Patient and visit characteristics related to physicians' participatory decision-making style. Medical Care 33(12) 1176-1187.

Koch-Laking, A., M. K. Park, E. Tweed. 2010. Does DTC advertising affect physician prescribing habits? Clinical Inquiries 59(11) $649-650$.

Kolsarici C., D. Vakratsas. 2010. Category- versus brand-level advertising messages in a highly regulated environment. Journal of Marketing Research 47(6) 1078-1089.

Kravitz, R. L. 2000. Direct-to-consumer advertising of prescription drugs: Implications for the patient-physician relationship. Journal of the American Medical Association 284(17) 2244. 
Kravitz, R. L., R. A. Bell, R. Azari, S. Kelly-Reif, E. Krupat, D. H. Thom. 2003. Direct observation of requests for clinical services in office practice: What do patients want and do they get it. Archives of Internal Medicine 163 1673-1681.

Kravitz, R. L., R. M. Epstein, M. D. Feldman, C. E. Franz, R. Azari, M. S. Wilkes, L. Hinton, P. Franks. 2005. Influence of patients' requests for direct-to-consumer advertised antidepressants. Journal of the American Medical Association 293(16) 19952002 .

Kremer, S. T. M., T. H. A. Bijmolt, P. S. H. Leeflang, J. E. Wieringa. 2008. Generalizations on the effectiveness of pharmaceutical promotional expenditures. International Journal of Research in Marketing 25 234-246.

Lillie-Blanton M., M. Brodie, D. Rowland, D. Altman, M. McIntosh. 2000. Race, ethnicity, and the health care system: Public perceptions and experiences. Medical Care Research and Review 57 218-235.

Ling, D. C., E. R. Berndt, M. K. Kyle. 2002. Deregulating direct-to-consumer marketing of prescription drugs: Effects on prescription and over-the-counter product sales. Journal of Law and Economics 45(2) 691-723.

Lupton, D. 1997. Consumerism, reflexivity and the medical encounter. Social 45(3) 373-381.

Macias, W., L. S. Lewis. 2003. A content analysis of direct to consumer (DTC) prescription drug web sites. Journal of Advertising 32(4) $43-55$.

Mack, J. 2009. The empowered patient: What it means for pharma marketers. Pharma Marketing News 8(4) 2-7.

Manchanda, P., P. E. Rossi, P. K. Chintagunta. 2005. Response modeling with nonrandom marketing-mix variables. Journal of Marketing Research 41(4) 467-478.

Manchanda, P., Y. Xie, N. Youn. 2008. The role of targeted communication and contagion in product adoption. Marketing Science 27(6) 961-976.

Mastin T., J. L. Andsager, J. Choi, K. Lee. 2007. Health disparities and direct-to-consumer prescription drug advertising: A content analysis of targeted magazine genres, 1992-2002. Health Communication 22(1) 49-58.

McKillen, D. 2002. Consumers depend on brand-specific web sites for information. Medical Marketing \& Media 37(5) 12-14.

McKinlay, J. 1996. Some contributions from the social system to gender inequalities in heart disease. Journal of Health and Social Behavior 37(1) $1-26$.

Medical Marketing and Media. 2002. DTC success measured by drug requests. Medical Marketing \& Media 37(6) 6.

Meyerhoefer, C. D., S. H. Zuvekas. 2008. The shape of demand: What does it tell us about direct-to-consumer marketing of antidepressants? B.E. Journal of Economic Analysis and Policy: Advances in Economic Analysis and Policy 8(2-4).

Mintzes, B., M. L. Barer, R. L. Kravitz, B. Bassett, J. Lexchin, A. Kazanjian, R. G. Evans, R. Pan, S. A. Marion. 2003. How does direct-to-consumer advertising (DTCA) affect prescribing? A survey in primary care environments with and without legal DTCA. Canadian Medical Association Journal 169(5) 405-412.

Mizik, N., R. Jacobson. 2004. Are physicians 'easy marks'? Quantifying the effects of detailing and sampling on new prescriptions. Management Science 50(12) 1704-1715.

Mundy, A. 2008.Making a name for drugs without using their names; Some ads highlight only web addresses so side effects don't have to be listed. The Wall Street Journal August 29, B.1.

Musalem, A., E. Bradlow, J. Raju. 2008. Who's got the coupon? Estimating consumer preferences and coupon usage from aggregate data. Journal of Marketing Research 45 715-730.

Nevo, A. 2001. Measuring market power in the ready-to-eat cereal industry. Econometrica 69(2) 307-342.

Omonuwa, S. C. 2001. Health disparity in Black women: lack of pharmaceutical advertising in Black- vs. White-oriented magazines. Journal of the National Medical Association 93(7-8) 263-266.

Parnes, B., P. C. Smith, C. Gilroy, J. Quintela, C. B. Emsermann, L. M. Dickinson, J. M. Westfall. 2009. Lack of impact of directto-consumer advertising on the physician-patient encounter in primary care: A SNOCAP report. Annals of Family Medicine 7(1) $41-46$.

Paterniti, D. A., T. L. Fancher, C. S. Cipri, S. Timmermans, J. Heritage, R. L. Kravitz. 2010. Getting to “No". Archives of Internal Medicine 170(4) 381-388.

Peterson, E., L. Shaw, E. DeLong, D. Pryor, R. Califf, D. Mark. 1997. Racial variation in the use of cardiac revascularization procedures: are the differences real? Do they matter? The New England Journal of Medicine 336 480-486. 
Prosser H., S. Almonda, T. Walley. 2003. Influences on GPs' decision to prescribe new drugs - the importance of who says what. Family Practice 20(1) 61-68.

Rama, J., J. Singh. 2009. Pragmatic learning theory: Distributive consumer learning in online communities. Working paper.

Rosenthal, M. B., E. R. Berndt, J. M. Donohue, A. M. Epstein, R. G. Frank. 2003. Demand effects of recent changes in prescription drug information. D. M. Cutler, A. M. Garber, eds. Frontiers in Health Policy Research Vol. 6, MIT Press: Boston, MA, 1-26.

Schwartz, R. K., S. B. Soumerai, J. Avorn. 1989. Physician motivations for nonscientivic drug prescribing. Social Science and Medicine 28(6) 577-582.

Sehili, S., E. H. Elbasha, D. G. Moriarty, M. M. Zack. 2004. Inequalities in self-reported physical health in the United States, 19931999. Health Economics 14(4) 377-389.

Sonel, A. F., C. B. Good, J. Mulgund, M. T. Roe, W. B. Gibler, S. C. Smith Jr, M. G. Cohen, C. V. Pollack Jr, E. M. Ohman, E. D. Peterson. 2005. Racial variations in treatment and outcomes of Black and White patients with high-risk non-ST-elevation acute coronary syndromes: Insights from CRUSADE (Can Rapid Risk Stratification of Unstable Angina Patients Suppress Adverse Outcomes With Early Implementation of the ACC/AHA Guidelines?). Circulation 111 1225-1232.

Steingart, R. 1991. Sex differences in management of coronary artery disease. New England Journal of Medicine 325(4) 221 -225.

Street, R. L. Jr., D. B. Buller. 1988. Patients' characteristics affecting physician-patient nonverbal communication. Human Communication Research 15(1) 60-90.

Street, R. L., H. S. Gordon, M. M. Ward, E. Krupat, R. L. Kravitz. 2005. Patient participation in medical consultations: Why some patients are more involved than others. Medical Care 43(10) 960-969.

Stevenson, F. A., A. C. Barry, N. Britten, N. Barber, C. P. Bradley. 2000. Doctor-patient communication about drugs: the evidence for shared decision making. Social Science and Medicine 50 829-840.

Sudhir, K. 2001. Structural analysis of competitive pricing in the presence of a strategic retailer. Marketing Science 20(3), 244264.

Tamayo-Sarver, J. H., S. W. Hinze, R. K. Cydulka, D. W. Baker. 2003. Racial and ethnic disparities in emergency department analgesic prescription. American Journal of Public Health 93(12) 2067-2073.

Tanner, M. A., W. H. Wong. 1987. The calculation of posterior distributions by data augmentation. Journal of the American Statistical Association 82 528-549.

Tentler A., J. Silberman, D. A. Paterniti, R. L. Kravitz, R. M. Epstein. 2008. Factors affecting physicians' responses to patients' requests for antidepressants: Focus group study. Journal of General Internal Medicine 23(1) 51-57.

Todd, K. H., N. Samaroo, J. R. Hoffman. 1993. Ethnicity as risk factor for inadequate emergency department analgesia. Journal of the American Medical Association 269(12) 1537-1539.

Train, K. E. 2003. Discrete Choice Methods with Simulation. Cambridge University Press, New York, NY.

Uhlmann, R. F., T. S. Inui, R. E. Pecoraro, W. B. Carter. 1988. Relationship of patient request fulfillment to compliance, glycemic control, and other health care outcomes in insulin-dependent diabetes. Journal of Internal Medicine 3(5) 458-463.

Van Ryn, M., J. Burke. 2000. The effect of patient race and socio-economic status on physicians' perceptions of patients. Social Science and Medicine 50 813-828.

Vakratsas, D., T. Ambler. 1999. How advertising works: What do we really know? Journal of Marketing 63(1) 26-43.

Venkataraman, S., S. Stremersch. 2007. The debate on influencing doctors' decisions: Are drug characteristics the missing link? Management Science 53(11) 1688-1701.

Ventres, W., P. Gordon. 1990. Communication strategies in caring for the underserved. Journal of Health Care for the Poor and Underserved $1305-314$.

Villas-Boas, J. M., R. S. Winer. 1999. Endogeneity in brand choice models. Management Science 45(October) 1324-1338.

Villas-Boas, J. M., Y Zhao. 2001. The ketchup marketplace: Retailer, manufacturers, and individual consumers. Working paper, University of California, Berkeley, CA.

Wang, S. S. 2008. Drug-safety data: Too much information? The Wall Street Journal December 9, D.1.

Webb, S., M. Lloyd. 1994. Prescribing and referral in general practice: a study of patients' expectations and doctors' actions. British Journal of General Practice 44 165-169. 
Weiss, M. C., R. Fitzpatrick, D. K. Scott, M. J. Goldacre. 1996. Pressures on the general practitioner and decisions to prescribe. Family Practice 13(5) 432-438.

Weissman, J. S., D. Blumenthal, A. J. Silk, K. Zapert, M. Newman, R. Leitman. 2004. Consumers' reports on the health effects of direct-to-consumer drug advertising. Health Affairs- Web Exclusive W3 82-95.

Welch, C. R. J., H. N. Young. 2004. Marketing drugs, marketing health care relationships: a content analysis of visual cues in direct-to-consumer prescription drug advertising. Health Communication 16(2) 131-157.

Wenneker, M., A. Epstein. 1989. Racial inequalities in the use of procedures for patients with ischemic heart disease in Massachusetts. Journal of the American Medical Association 261(2) 253-257.

Werner, R. M., D. A. Asch, D. Polsky. 2005. Racial profiling: The unintended consequences of coronary artery bypass graft report cards. Circulation 111 1257-1263.

Wilkes, M. S., R. A. Bell, R. L. Kravitz. 2000. Direct-to-consumer prescription drug advertising: Trends, impact, and implications. Health Affairs 19(2) 110-128.

Wosinska, M. 2005. Direct-to-consumer advertising and drug therapy compliance. Journal of Marketing Research 42(3) 323-332.

Yang, S., Y. Chen, G. Allenby. 2003. Bayesian analysis of simultaneous demand and supply. Quantitative Marketing and Economics 1 251-275.

Yang, S., G. Allenby 2003. Modeling interdependent consumer preferences. Journal of Marketing Research 40(3) $282-294$.

Young, M., R. S. Klingle. 1996. Silent partners in medical care: A cross-cultural study of patient participation. Health Communication 8(1) 29-35.

Zachry, W. M., M. D. Shepherd, M. J. Hinich, J. P. Wilson, C. M. Brown, K. A. Lawson. 2002. Relationship between direct-toconsumer advertising and physician diagnosing and prescribing. American Journal of Health-System Pharmacy 59(1) $42-49$. 